\title{
Increased immunosuppression impairs tissue homeostasis with aging and age-related diseases
}

\author{
Antero Salminen ${ }^{1}$ (D) \\ Received: 1 June 2020 / Revised: 21 September 2020 / Accepted: 29 September 2020 / Published online: 6 October 2020 \\ (C) The Author(s) 2020
}

\begin{abstract}
Chronic low-grade inflammation is a common hallmark of the aging process and many age-related diseases. There is substantial evidence that persistent inflammation is associated with a compensatory anti-inflammatory response which prevents excessive tissue damage. Interestingly, the inflammatory state encountered with aging, called inflammaging, is associated with the antiinflammaging process. The age-related activation of immunosuppressive network includes an increase in the numbers of myeloid-derived suppressor cells (MDSC), regulatory T cells (Treg), and macrophages (Mreg/M2c). Immunosuppressive cells secrete several anti-inflammatory cytokines, e.g., TGF- $\beta$ and IL-10, as well as reactive oxygen and nitrogen species (ROS/RNS). Moreover, immunosuppressive cells suppress the function of effector immune cells by catabolizing L-arginine and tryptophan through the activation of arginase 1 (ARG1) and indoleamine 2,3-dioxygenase (IDO), respectively. Unfortunately, the immunosuppressive armament also induces harmful bystander effects in neighboring cells by impairing host tissue homeostasis. For instance, TGF- $\beta$ signaling can trigger many age-related degenerative changes, e.g., cellular senescence, fibrosis, osteoporosis, muscle atrophy, and the degeneration of the extracellular matrix. In addition, changes in the levels of ROS, RNS, and the metabolites of the kynurenine pathway can impair tissue homeostasis. This review will examine in detail the harmful effects of the immunosuppressive cells on host tissues. It seems that this age-related immunosuppression prevents inflammatory damage but promotes the tissue degeneration associated with aging and age-related diseases.
\end{abstract}

\section{Key messages}

- Low-grade inflammation is associated with the aging process and age-related diseases.

- Persistent inflammation activates compensatory immunosuppression with aging.

- The numbers of immunosuppressive cells increase with aging and age-related diseases.

- Immunosuppressive mechanisms evoke harmful bystander effects in host tissues.

- Immunosuppression promotes tissue degeneration with aging and age-related diseases.

Keywords Aging · Alzheimer's $\cdot$ Immunometabolism $\cdot$ Immunosenescence $\cdot$ Nitric oxide $\cdot$ Tissue degeneration

\section{Introduction}

The remodeling of the immune system including the presence of chronic low-grade inflammation is one hallmark of the aging process $[1,2]$. This age-related immune state has commonly been called inflammaging. Systemic chronic inflammation has also been implicated in many age-related diseases,

Antero Salminen

antero.salminen@uef.fi

1 Department of Neurology, Institute of Clinical Medicine, University of Eastern Finland, P.O. Box 1627, FI-70211 Kuopio, Finland aggravating the pathology of these diseases, e.g., cardiovascular diseases, chronic kidney disease, non-alcoholic fatty liver diseases, and neurodegenerative diseases [3]. Currently, the molecular origin of age-related inflammation needs to be clarified. Nonetheless, there is substantial evidence that persistent inflammation is associated with a compensatory antiinflammatory response which prevents excessive tissue damage in the conditions of chronic inflammation [4, 5]. Interestingly, inflammaging is also associated with the antiinflammaging process $[6,7]$, i.e., not only is there an increased level of anti-inflammatory cytokines but there is also clear evidence that the numbers of several immunosuppressive cells are augmented during the aging process [8] (see below). 
Similar effects have been observed in many age-related diseases, e.g., in atherosclerosis [9] and non-alcoholic fatty liver disease [10]. Immunosuppressive cells possess diverse immunosuppressive mechanisms which suppress the function of effector immune cells in inflamed tissues. However, only a few of these activities are specifically targeted to immune cells but in contrast, they can induce harmful bystander effects in the neighboring cells of host tissues. For instance, TGF- $\beta$, an anti-inflammatory cytokine, secreted by many immunosuppressive cells, can provoke degenerative changes in tissues which are similar to those induced by the aging process (see below). Moreover, suppressor cells induce a shortage of some amino acids in inflamed tissues which affects not only the immune cells but also the cells of host tissues. I will thoroughly examine the possibility that the activation of immunosuppressive cells causes degenerative bystander effects in host tissues with aging.

\section{Chronic inflammation provokes compensatory immunosuppression}

Severe inflammatory conditions, e.g., autoimmune diseases, pathogen-induced sepsis, and traumatic injuries, induce a systemic state called the systemic inflammatory response syndrome (SIRS) [5, 11]. The SIRS-related disorders are associated with a compensatory anti-inflammatory syndrome (CARS) which prevents detrimental multiple organ failure $[5,12]$. The life-threatening SIRS/CARS condition has also been termed the persistent inflammation, immunosuppression, and catabolism syndrome (PICS). It seems that the immunosuppressive CARS state can concomitantly appear with the proinflammatory SIRS phase although in many disorders, e.g., in sepsis and trauma, the SIRS condition dominates during the early phase, whereas immunosuppressive responses control the later phases $[5,13]$. The common characteristics of CARS involve (i) the induction of emergency myelopoiesis, especially myeloid-biased hematopoietic stem cell differentiation, (ii) the excessive expansion of myeloid-derived suppressor cells (MDSC) and regulatory T cells (Treg), and (iii) the increased expression of anti-inflammatory cytokines in both circulation and affected tissues [5, 13]. Given that inflammatory factors are the main inducers of immunosuppressive cells, e.g., MDSCs $[14,15]$, we can expect that an excessive inflammation of SIRS state stimulates the immunosuppressive CARS response to counteract the detrimental inflammatory injuries occurring in host tissues.

There is abundant evidence that it is not only severe systemic inflammation which induces compensatory immunosuppression but also local immune activation can induce the stimulation of immunosuppression, e.g., in tumors and tissue transplantation $[4,16,17]$. In particular, compensatory immunosuppression is associated with non-resolving inflammatory states, e.g., autoimmune diseases, atherosclerosis, and tumors. In this respect, the aging process and Alzheimer's disease can be considered as non-resolving conditions even though the persistent perpetrator is unknown. In tumors, chronic inflammation creates an immunosuppressive microenvironment, e.g., involving the activation of MDSCs and Tregs, which allows the escape of tumor cells from immune surveillance [16]. Interestingly, senescent cells, present in both tumors and aged tissues, secrete several inflammatory factors [18-20]. Senescent cells are most likely an important source of chronic inflammation in aged tissues since they are able to modify the phenotypes of immune cells and thus enhance immunosuppression in tumors and aged tissues (see below) (Fig. 1).

\section{Immunosuppressive network}

The microenvironment has a critical role in the regulation of immune cell populations and their functions in tissues. Immune cells possess a great plasticity to modify their phenotypes and activities according to the changes in their microenvironment. Inflammatory responses linked to tissue injuries, infections, and tumors are potent inducers of the changes in immune homeostasis. For instance, in acute inflammation, macrophages polarize towards the pro-inflammatory M1 subtype, whereas in chronic inflammatory conditions, they can display anti-inflammatory M2 properties [21]. Inflammation is an alarming response which not only controls the phenotype of tissue-resident immune cells but can also stimulate myelopoiesis in the bone marrow and recruit immune cells into inflamed tissues. Subsequently, the infiltrated immune cells, e.g., monocytes, can become differentiated into other subtypes of myeloid cells in response to environmental signals. Interestingly, the cells of host tissues can educate immune cells by secreting a diverse set of soluble factors. For instance, tumor cells are able to educate immune cells into immunosuppressive phenotypes, e.g., tumor-associated macrophages (TAM) [22]. However, this property is not unique to cancer cells since many other cells, normal or transformed, can educate immune cells, e.g., fibroblasts [23] and keratinocytes [24]. In addition, changes in the extracellular matrix can regulate the properties and activation level of immune cells [25]. The immune system is a co-operative network which can control the activities and phenotypes of immune cells on the basis of the microenvironmental conditions.

Chronic inflammatory disorders remodel the phenotypes of immune cells towards the anti-inflammatory activities in inflamed tissues. The immunosuppressive phenotypes have been called regulatory subtypes since they can inhibit the functions of both myeloid and lymphoid effector cells $[8$, $17,26]$. This immunosuppressive network involves regulatory $\mathrm{T}$ (Treg) and B (Breg) cells of lymphoid lineage. 


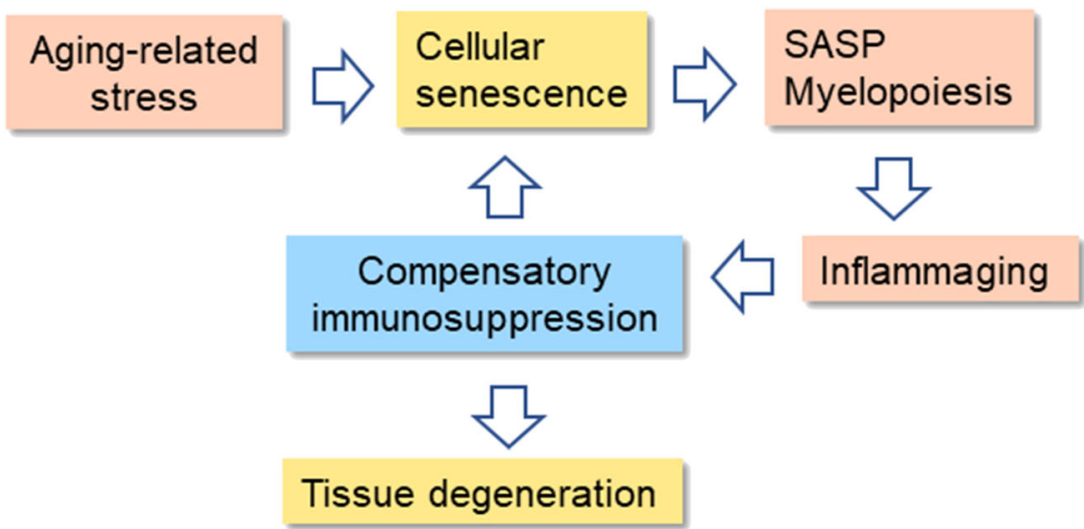

Fig. 1 The feed-forward regulation between cellular senescence, inflammaging, and compensatory immunosuppression in the aging process. Several age-related stresses induce the accumulation of senescent cells into tissues. The pro-inflammatory phenotype (SASP) of senescent cells enhances the myelopoiesis and the recruitment of immune cells into aging tissues. The inflammaging state evokes compensatory

Correspondingly, the immunosuppressive myeloid cells include myeloid-derived suppressor cells (MDSC) as well as regulatory macrophages (Mreg/M2c), dendritic cells (DCreg), natural killer cells (NKreg), and type II natural killer T cells (NKT) (Fig. 2). MDSCs are a heterogeneous group of immature myeloid cells which originate from myelopoiesis in the bone marrow, especially many inflammatory factors stimulate the generation of MDSCs $[15,17]$. There are two types of MDSCs, i.e., the monocytic (M-MDSC) and polymorphonuclear (PMN-MDSC) subsets. Interestingly, MDSCs can be matured into other myeloid regulatory cells in inflamed tissues. Given that MDSCs secrete immunosuppressive factors, they can enhance or maintain the immunosuppressive properties of other regulatory cell types. Tregs are a heterogeneous group of $\mathrm{T}$ cells including thymic (tTreg), peripheral (pTreg), and inducible (iTreg) subtypes [27]. Tregs are the major immunosuppressive cells which can inhibit the functions of helper and cytotoxic T cells as well as those of B cells. They can also promote the generation of DCregs and M2 antiinflammatory macrophages. Breg cells are also a diverse population of suppressive B cells which induce immunosuppressive processes by secreting IL-10 cytokines [28]. It is known that MDSCs promote the functions of Bregs [29], whereas Bregs promote the expansion of Tregs [30]. This illustrates well the co-operation between MDSCs, Tregs, and Bregs. The microenvironmental signals of inflamed tissues have a crucial role in the generation of other regulatory subtypes, i.e., DCregs, Mregs/M2c, and NKregs [8, 17, 26]. The immunosuppressive phenotypes of these regulatory myeloid cells have been augmented by the cytokines secreted by MDSCs, Tregs, and Bregs. Conversely, the suppressive subsets of myeloid cells inhibit their effector counterparts by secreting antiinflammatory cytokines. Briefly, the members of immunosuppressive network co-operate to potentiate their suppressive immunosuppression which counteracts the low-grade inflammation present in aged tissues. Consequently, immunosuppression impairs the clearance of senescent cells, i.e., it enhances inflammaging and immunosuppression. Increased immunosuppression with aging impairs the maintenance of tissue homeostasis and induces the degenerative changes evident in aging tissues

activities in order to counteract the pro-inflammatory responses in chronic disorders (Fig. 2).

The immunosuppressive network possesses an armament of diverse mechanisms to enhance their own suppressive capacity which inhibits the functions of immune system in chronic inflammatory conditions. However, the targets are not only immune cells since the tools exert many bystander effects in the host tissues inducing the degeneration of tissues in chronic disorders. Anti-inflammatory cytokines secreted by regulatory immune cells are the key messengers which induce the immunosuppressive responses in inflamed tissues [31-33]. IL-10 and TGF- $\beta$ are the major anti-inflammatory cytokines although there are some other immunosuppressive cytokines, e.g., IL-4, IL-11, IL-13, IL-35, and IL-1 receptor antagonist (IL-1ra). The secretion of the anti-inflammatory cytokines occurs in a context-dependent manner. Another important immunosuppressive mechanism is the increased expression of amino acid-catabolizing enzymes leading to a shortage of certain amino acids in inflamed tissues [34, 35] (Fig. 3). The robust induction of arginase 1 (ARG1) and indoleamine 2,3-dioxygenase (IDO) in suppressive cells consumes arginine and tryptophan, respectively, from the microenvironment which consequently inhibits protein synthesis and ultimately suppresses the proliferation of pro-inflammatory cells in chronic disorders. Moreover, any deficiency of arginine and tryptophan will also affect protein synthesis in the cells of host tissues. It is not only the shortage of amino acids but also the activations of ARG1 and IDO generate metabolites which disturb the metabolism of host tissues. Given that arginine is the shared substrate for ARG1 and nitric oxide synthase (NOS), the induction of ARG1 inhibits the generation of nitric oxide (NO) [36] (Fig. 3). Correspondingly, the activation of IDO stimulates the kynurenine pathway which is involved in the pathogenesis of many chronic diseases [37]. Although the activation of ARG1 


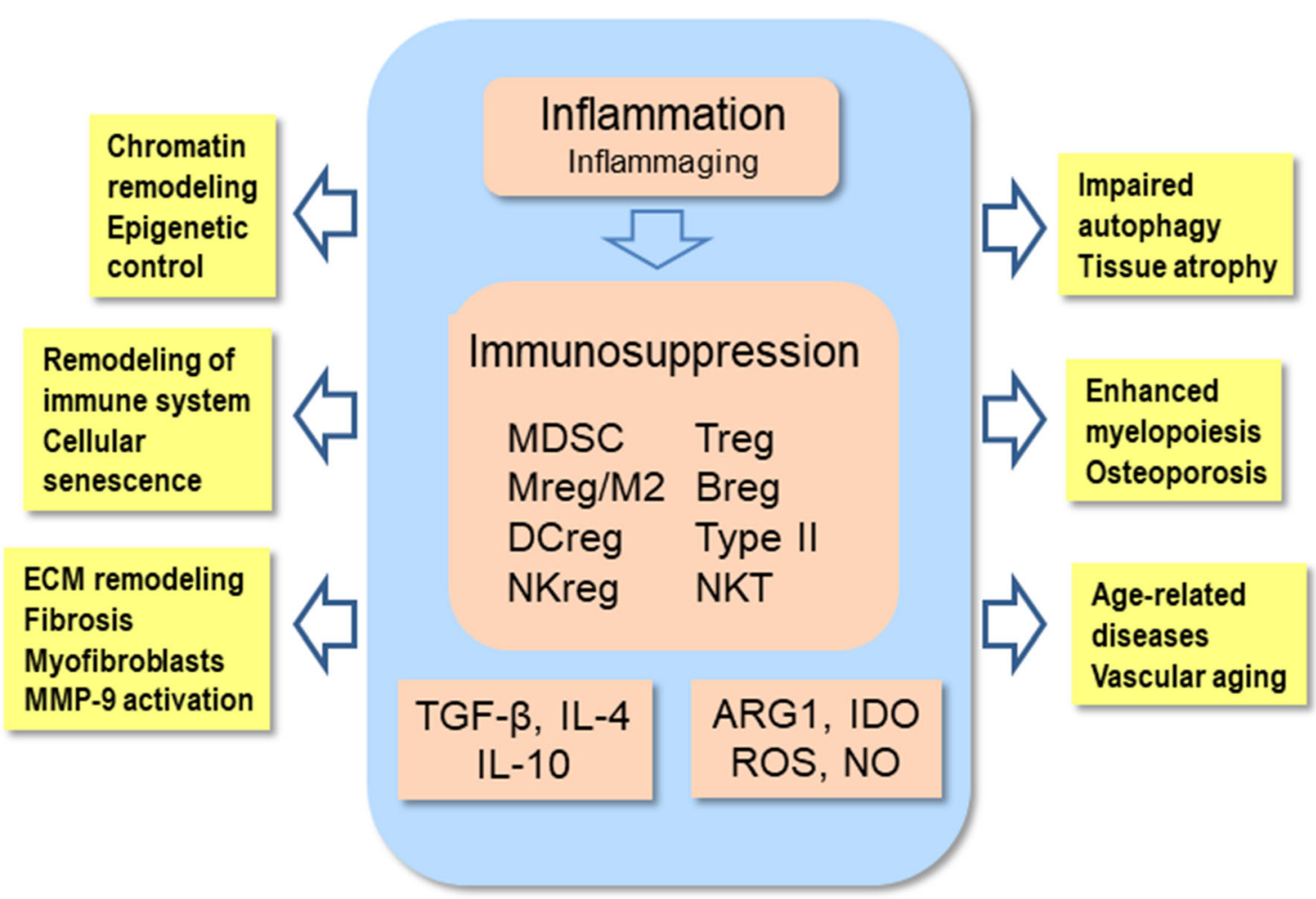

Fig. 2 Chronic low-grade inflammation elicits compensatory immunosuppression by activating the cells of the immunosuppressive network. Immunosuppression is generated by the secretion of anti-inflammatory cytokines, e.g., TGF- $\beta$ and IL-10, as well as through the release of ROS and NO. The activation of ARG1 and IDO enzymes induces the catabolism of L-arginine and tryptophan, respectively. Immunosuppression provokes many pathological changes in host tissues which are similar to those encountered during the aging process and in age-related diseases.

and IDO has an indispensable role in the maintenance of immunosuppression, concurrently, it exposes host tissues to many detrimental bystander effects (Figs. 2 and 3).

\section{Cellular senescence promotes inflammaging and immunosuppression}

There are a number of theories on the mechanisms driving the aging process, i.e., a spectrum of diverse mechanisms ranging from damage hypotheses to programmed theories. Recently, the roles of cellular senescence and the remodeling of the immune system have received considerable attention $[2,38]$. An irreversible arrest of cell cycle is one major hallmark of cellular senescence although there are other common characteristics, e.g., resistance to apoptosis, flat cell morphology and nuclear changes, dysfunctions in mitochondria and the lysosomal system, and several alterations in the maintenance of proteostasis. Interestingly, senescent cells display a secretory phenotype and thus this state has been called the senescenceassociated secretory phenotype (SASP) [39]. For instance, senescent cells not only secrete inflammatory mediators,
ARG1, arginase 1; Breg, regulatory B cell; DCreg, regulatory dendritic cell; IDO, indoleamine 2,3-dioxygenase; IL, interleukin; MDSC, myeloid-derived suppressor cell; MMP-9, matrix metalloproteinase-9; Mreg/M2, regulatory macrophage; NKreg, regulatory natural killer cell; NO, nitric oxide; ROS, reactive oxygen species; TGF- $\beta$, transforming growth factor- $\beta$; Treg, regulatory T cell; Type II NKT, Type II natural killer $\mathrm{T}$ cell

e.g., interleukins, chemokines, and colony-stimulating factors, but also growth factors, proteases, and extracellular matrix proteins $[19,39,40]$. The secretion of exosomes is also increased from senescent cells [41, 42]. It seems that senescent cells secrete pro-inflammatory factors to alert the immune system about imminent danger and to enhance the elimination of senescent cells. It is likely that senescent cells displaying the SASP properties are the most important source of the inflammaging process which evokes the counteracting immunosuppressive response (Fig. 1).

\section{Senescent cells accumulate into tissues with aging}

There is convincing evidence that senescent cells accumulate within tissues during the aging process $[43,44]$. The in vivo biomarkers of senescent cells include an enhanced expression of p16INK4a and SA- $\beta-$ Gal as well as the appearance of senescence-associated heterochromatin foci (SAHF). An increase in the numbers of senescent cells is also associated with many age-related diseases, e.g., age-dependent hepatic steatosis [45] and cardiovascular diseases [46]. Ogrodnik et al. [45] reported that senescent hepatocytes promoted the 
Fig. 3 Amino acid catabolism caused by ARG1 and IDO triggers a shortage of L-arginine and tryptophan, disturbing the homeostasis of host tissues. IDO activates the kynurenine pathway which produces several toxic metabolites. GCN2/eIF2 $\alpha /$ ATF4 signaling inhibits protein synthesis and activates the integrated stress response. ARG1, arginase 1; ATF4, activating transcription factor 4 ; eIF $2 \alpha$, eukaryotic translation initiation factor $2 \alpha$; GCN2, general control non-depressible 2; IDO, indoleamine 2,3-dioxygenase; mTOR, mechanistic target of rapamycin

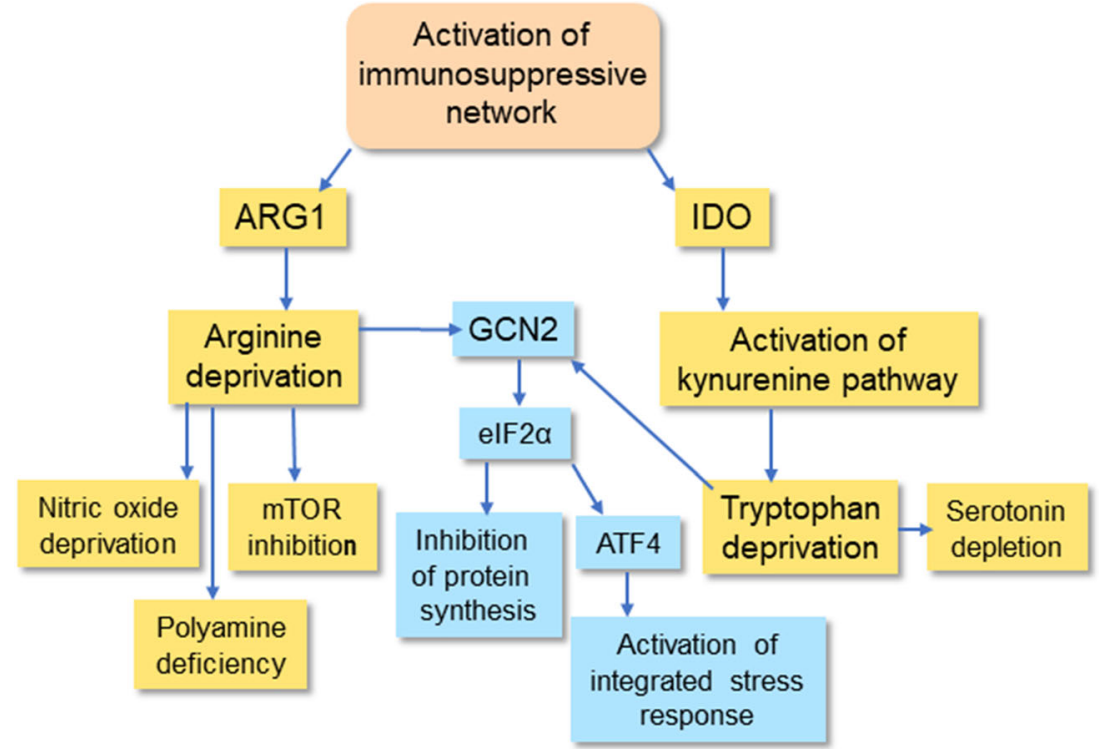

severity of age-dependent steatosis in mouse liver, whereas the suicide gene-mediated clearance of senescent hepatocytes reduced the accumulation of fat into mouse liver with aging. Interestingly, there are studies indicating that senescent cells can induce a form of bystander senescence of neighboring cells in a paracrine manner $[47,48]$. The paracrine transmission of senescence may be mediated by exosomes [49] and soluble SASP components, e.g., IL- $1 \alpha$ and TGF- $\beta$ [50]. In addition to the enhanced production of senescent cells, it seems that the reduced clearance of senescent cells also augments the accumulation of senescent cells into aging tissues. Sagiv et al. [51] demonstrated that the surveillance and clearance of senescent human fibroblasts were mediated by the NKG2D receptors of NK cells. However, the accumulation of pro-inflammatory senescent cells into tissues evokes a counteracting response, i.e., the recruitment and expansion of immunosuppressive cells within these tissues (see above) [8]. It is known that MDSCs and Tregs can inhibit the cytotoxicity of NK cells $[52,53]$ thus preventing the clearance of senescent cells from aging tissues. It seems that there exists a feed-forward regulation between the accumulation of senescent cells and the age-related immunosuppression (Fig. 1).

\section{Inflammatory phenotype of senescent cells promotes inflammaging and immunosuppression}

The inflammatory phenotype is a hallmark of senescent cells although the type of stress stimuli and the actual cells involved affect the profiles secreted by senescent cells [19, 38, 54]. For instance, Wiley et al. [54] reported that the mitochondrial dysfunction-associated senescence (MiDAS) did not induce the secretion of the cytokines of the IL-1 family in human fibroblasts and progeroid mice in vivo. The most secreted interleukins have included IL-6, IL-7, IL-1 $\beta$, and IL-8 in the different models [19]. Senescent cells also robustly (over 4fold) secrete colony-stimulating factors (CSF), e.g., GM-CSF and G-CSF. Interestingly, GM-CSF is a potent driver of chronic inflammation since it activates myelopoiesis and promotes the expansion and differentiation of MDSCs and Tregs $[55,56]$. It is known that there is a significant increase in myelopoiesis with aging, whereas lymphopoiesis is downregulated [57]. Senescent cells also secrete chemokines and other chemoattracting molecules, e.g., CCL2, CCL3, CCL8, and CXCL1,2,3 (over 4-fold), which recruit myeloid cells into inflamed tissues [19]. A low-grade inflammation, i.e., inflammaging, is associated with a significant increase in the levels of many inflammatory mediators in peripheral tissues and circulation $[2,7,40]$. Benayoun et al. [40] demonstrated that the transcriptional trajectories of several innate immunity pathways were robustly increased with aging in many tissues of humans and rodents. In particular, the NF-KB and JAK/ STAT signaling pathways were most evidently induced with aging. NF-KB signaling can be a driving force for both the proinflammatory and anti-inflammatory responses, e.g., promoting the differentiation and activity of MDSCs and Tregs $[58,59]$. Moreover, JAK/STAT signaling is the major inducer of the differentiation and expansion of MDSCs [58]. It is not only the proinflammatory processes which increase with aging but also the anti-inflammatory responses, termed antiinflammaging, are augmented during the aging process [6-8]. The situation is reminiscent of the compensatory immunosuppression encountered in inflammatory diseases (see above). It is also known that different cellular stresses, e.g., oxidative stress and ER stress, are potent inducers of inflammation which enhances the differentiation and expansion of immunosuppressive MDSCs [60-62]. Ruhland et al. [20] demonstrated that the upregulation of senescent stromal cells in mouse skin provoked inflammation which promoted the 
appearance of an immunosuppressive microenvironment, i.e., senescent cells augmented the levels of MDSCs and Tregs in mouse skin. They also reported that the senescent stroma in mouse skin decreased immune surveillance which enhanced tumorigenesis. Interestingly, the presence of senescent stromal cells was significantly increased in the skin of elderly people, concurrently with the accumulation of MDSCs. This indicates that the age-related increase of pro-inflammatory senescent cells might promote a compensatory immunosuppression which prohibits the clearance of senescent cells in both tumors and aged tissues.

\section{Evidence on the increased immunosuppression in the aging process}

There are some difficulties encountered in determining whether compensatory immunosuppression is associated with the aging process and age-related diseases since immune cells are exceedingly plastic cells, i.e., they can become gradually polarized between the proinflammatory and antiinflammatory phenotypes in a context-dependent manner $[8$, 63]. For instance, the anti-inflammatory cytokines, e.g., IL-10 and TGF- $\beta$, can induce the conversion of myeloid and lymphoid cells towards the immunosuppressive regulatory phenotypes, i.e., the network co-operates and potentiates its suppressive properties according to the demands of the microenvironment. In addition, there are many technical difficulties, e.g., in the application of flow cytometric techniques in tissue assays. However, there is convincing evidence that the numbers of MDSCs increase with aging in the circulation of humans and mice [64, 65]. Verschoor et al. [65] reported that the numbers of PMN-MDSCs were significantly increased in the circulation of both community-dwelling seniors (6176 years, $n=45)$ and frail elderly people (67-99 years, $n=$ 131 ) as compared with the PMN-MDSC level of healthy adults (19-59 years, $n=41)$. This phenomenon does not only occur in the circulation since it has been reported that the numbers of MDSCs were augmented with aging in mouse bone marrow, spleen, and lymph nodes $[64,66]$ as well as in human and mouse skin [20]. Flores et al. [66] demonstrated that the age-related increase in the presence of MDSCs in mouse bone marrow and spleen was induced by the activation of NF-KB signaling. They also revealed that the number of MDSCs was clearly increased in the bone marrow of the progeroid mouse mutants, BubRl and Erccl. There is substantial evidence that the presence of Tregs clearly increases with aging in the blood and lymphoid tissues of humans and mice $[67,68]$ as well as in mouse visceral adipose tissue [69] and skin [20]. Lages et al. [67] reported that the frequency of FoxP3-positive Tregs was significantly higher in the circulation of elderly participants (over 70 years, $n=16$ ) than in young adults (below 30 years, $n=16$ ). In addition, the occurrence of immunosuppressive M2 macrophages was found to increase with aging in mouse bone marrow, spleen, lungs, and skeletal muscles [70, 71]. It is not only the number of suppressive cells but also their immunosuppressive activities that are enhanced with aging. For instance, Enioutina et al. [64] demonstrated that the MDSCs isolated from the lymphoid organs of old mice significantly inhibited the antigen-induced $\mathrm{T}$ cell proliferation in vitro and the $\mathrm{T}$ cell-dependent antibody responses in vivo. These observations indicate that the expansion of immunosuppressive cells with aging impairs the function of $\mathrm{T}$ cells. Recently, I have reviewed the literature concerning the age-related activation of immunosuppressive network [8].

\section{Immunosuppression impairs tissue homeostasis in chronic inflammation}

The activation of immunosuppressive cells in chronic inflammation suppresses the functions of innate and adaptive immunity. In addition to the targeted mechanisms, e.g., checkpoint immune receptors, immunosuppressive cells secrete antiinflammatory cytokines and ROS compounds to inhibit immune responses. Moreover, these cells can also prevent the functions of immune cells by catabolizing L-arginine and tryptophan and thus induce a local shortage of these amino acids in the affected microenvironments. Nonetheless, these nontargeted mechanisms not only suppress immune cells but also impair the homeostasis of host tissues and consequently, they can provoke degenerative changes similar to those observed in the aging process and age-related diseases (Fig. 2).

\section{Anti-inflammatory cytokines}

\section{TGF- $\beta$}

The TGF- $\beta$ family of mammals involves three TGF- $\beta$ isoforms, i.e., TGF- $\beta 1$, TGF- $\beta 2$, and TGF- $\beta 3$, which control both the SMAD-dependent and independent pathways via the activation of TGF- $\beta$ receptors (TGF- $\beta$ R 1 and TGF- $\beta$ R2) [31]. The expression of TGF- $\beta$ cytokines as well as that of TGF- $\beta$ receptors displays low tissue specificity (Human Protein Atlas) although the activated immunosuppressive cells are the major source of TGF- $\beta$ cytokines in chronic inflammation. The activation of TGF- $\beta$ signaling is also controlled by many accessory proteins, e.g., latencyassociated peptides and distinct integrins [72]. TGF- $\beta$ is a pivotal cytokine in the regulation of the variety of functions undertaken by both innate and adaptive immunity $[31,73]$. Not only does TGF- $\beta$ signaling regulate immune responses but it also controls cell fates during development and many pathological conditions, e.g., cellular senescence, fibrosis, and tumorigenesis. Because of the diversity of the signaling mechanisms, TGF- $\beta$ can generate both beneficial and detrimental 
responses in a context-dependent manner [74]. Inflammatory mediators stimulate the secretion of TGF- $\beta$ from many immune cells, e.g., Tregs, MDSCs, M2 macrophages, and dendritic cells produce TGF- $\beta$ cytokines. TGF- $\beta$ is a potent antiinflammatory cytokine which enhances the resolution of inflammatory insults by suppressing immune activity, e.g., through the activation of immunosuppressive network [31, 73]. For instance, TGF- $\beta$ affects the myeloid cells by (i) enhancing the switch of pro-inflammatory M1 macrophages towards their immunosuppressive M2 phenotype, (ii) decreasing the cytotoxicity of neutrophils and NK cells, and (iii) reducing antigen presentation by dendritic cells [73]. In particular, TGF- $\beta$ signaling regulates the development of T lymphocytes in the thymus, promotes their differentiation into special $\mathrm{T}$ cell subtypes, and finally, controls their activities in diverse pathological conditions. For instance, TGF- $\beta$ suppresses the functions of CD4 and CD8 T cells, whereas it stimulates the expression of the FoxP3 gene in CD4 T cells and thus triggers their differentiation into immunosuppressive Treg cells [31]. TGF- $\beta$ and IL-10 are the major immunosuppressive cytokines which not only suppress inflammatory responses but simultaneously potentiate the suppressive properties of other immune cells including the immunosuppressive network. This indicates that immunosuppressive cells act as a co-operative network which has an important role in chronic inflammatory conditions, e.g., in the aging process [8].

TGF- $\beta$ signaling does not only suppress the functions of immune cells but it can also arrest the cell cycle and induce cellular senescence in different non-immune cells $[75,76]$. For instance, TGF- $\beta$ stimulated the expression of p16INK4a and p19ARF and subsequently induced the growth arrest and senescence of mouse keratinocytes [77]. There is substantial evidence that TGF- $\beta$ stimulates the expression of cyclindependent kinase inhibitors (CDKI), e.g., p15, p16, p21, and $\mathrm{p} 27$, which consequently induce cellular senescence $[75,76]$. TGF- $\beta$ can also inhibit the expression of human telomerase (hTERT) and thus provoke the attrition of telomeres which subsequently triggers cellular senescence [75]. Rapisarda et al. [78] demonstrated that the integrin $\beta 3$ subunit (ITGB3) activated TGF- $\beta$ signaling and accelerated senescence in human primary fibroblasts. The expression of ITGB3 protein and the components of TGF- $\beta$ signaling were abundantly expressed in fibroblasts derived from elderly humans. It is also known that TGF- $\beta$ signaling stimulates the NF- $\mathrm{KB}$-driven generation of the SASP state in many cell types [79]. The senescent cells exhibiting the SASP phenotype secrete diverse chemokine, cytokines, and colony-stimulating factors [19]. These inflammatory products are not only potent activators for the generation of myeloid suppressor cells, e.g., MDSCs, but they can also direct their recruitment into senescent tissues [80]. There can also appear age-related changes in the TGF- $\beta$ signaling pathway. van der Kraan [81] revealed that there are agerelated changes in the SMAD-dependent TGF- $\beta$ signaling in articular cartilage, i.e., the protective SMAD2/3 signaling was shifted towards the degeneration-linked SMAD1/5/8 signaling which provoked the generation of osteoarthritis with aging. It is likely that senescent cells are the major source of chronic low-grade inflammation observed in aging tissues (see above). Cellular senescence is an important tissue remodeling mechanism, e.g., during embryonic development and tissue injuries [82], but it seems that with aging, the accumulation of senescent cells enhances tissue degeneration. Currently, senescent cells are a challenging target for the development of anti-aging drugs. For instance, Baker et al. [83] demonstrated that the clearance of p16INK4a-positive cells from the wild-type mice extended the lifespan of both male and female mice. They also revealed that the accumulation of p16INK4a cells enhanced the aging process in mouse cardiac muscle. It seems that TGF- $\beta$ signaling has a significant role in the degeneration of tissues through the augmentation of cellular senescence in the age-associated chronic inflammation.

Fibrosis, i.e., an excessive accumulation of fibrous proteins in the extracellular matrix (ECM), is a typical pathological hallmark of aging in several organs, e.g., myocardium, kidney, lungs, and liver. There is convincing evidence that TGF- $\beta$ signaling is the crucial regulator in the formation of fibrosis with aging [84] (Fig. 2). The signaling pathways through the activation of SMAD2 and SMAD3 factors induce the expression and subsequently the secretion of collagens, fibronectins, proteoglycans, and glycosaminoglycans into the ECM. Different cell types, e.g., myofibroblasts and epithelial cells, can evoke the TGF- $\beta$-induced secretion of fibrous proteins in a context-dependent manner. TGF- $\beta$ signaling can also induce the differentiation of diverse cell types into myofibroblasts, e.g., through the process of epithelial/ endothelial-mesenchymal transition (EMT) [85]. Chronic inflammation is a common cause of fibrosis; most probably this can be attributed to the activation of immunosuppressive network. For instance, anti-inflammatory M2 macrophages are involved in the formation of fibrosis in the kidney [86]. Lebrun et al. [87] revealed that MDSCs promoted lung fibrosis by secreting TGF- $\beta 1$. Tregs also regulate lung fibrosis by controlling the activities of other T cells, e.g., Th17 cells [88]. Interestingly, there are studies indicating that the AMPK and Klotho signaling pathways, two potent anti-aging mechanisms, suppress the TGF- $\beta$-induced fibrogenic responses since they inhibit the signaling through the SMAD2/3 pathway $[89,90]$. Doi et al. [89] demonstrated that the secreted ectodomain of Klotho protein bounds to the TGF $\beta R 2$ protein, thus inhibiting the downstream signaling of TGF- $\beta$ and consequently preventing renal fibrosis. Klotho protein has many therapeutic effects, e.g., in vascular pathophysiology [91], which might be elicited through the blockade of TGF- $\beta$ signaling.

There is a close interaction between TGF- $\beta$ signaling and the components of the ECM [92]. For instance, ECM proteins 
can control the activation of TGF- $\beta$ signaling via integrin receptors [72]. Conversely, TGF- $\beta$ signaling stimulates the expression of enzymes which remodel ECM structures, e.g., matrix metalloproteinase-9 (MMP-9) [93] and several collagenases (MMP-1/13) and stromelysins (MMP-3/10/11) [94]. Toba et al. [95] demonstrated that the overexpression of MMP-9 in mouse macrophages enhanced the age-related cardiomyocyte hypertrophy, induced chronic low-grade inflammation in the myocardium, and increased cardiac fibrosis. Secreted proteinases cleave the danger-associated molecular patterns from extracellular matrix (ECM-derived DAMPs), e.g., aggrecan, biglycan, and decorin, which consequently activate the receptors of innate immunity [96]. It seems that ECM-derived DAMPs can promote both pro-inflammatory and anti-inflammatory responses in a context-dependent manner. For instance, Shao et al. [97] demonstrated that the MMP9-cleaved osteopontin (OPN) protein induced the expansion of mouse MDSCs which probably activated immunosuppressive network, as described above. Moreover, it is known that elastin-derived peptides enhance the pathogenesis of several age-related diseases, e.g., atherosclerosis [98]. Interestingly, ECM bioscaffolds are able to modulate immune responses, e.g., through macrophage polarization [99]. LoPresti and Brown [100] presented results indicating that the exposure of bone marrow macrophages to ECM biomaterials derived from the small intestine submucosa of aged pigs promoted the immune responses commonly induced by anti-inflammatory M2 macrophages. The interaction of TGF- $\beta$ signaling and matrix metalloproteinases has a crucial role in the remodeling of ECM with aging which affects stem cell homeostasis, tissue regeneration, and cellular senescence [101]. There is clear evidence that the expression of MMPs increases with aging in many tissues, e.g., those of MMP-1, MMP-9, and MMP-10 in human dermis [102]. Correspondingly, there are observations indicating that the number of MDSCs is increased in the skin of elderly people [20]. It seems that the age-related remodeling of ECM can be induced by TGF cytokines secreted by immunosuppressive cells (Fig. 2). However, it is not known whether the disturbances in ECM might precede the accumulation of immunosuppressive cells into tissues.

The aging process increases myelopoiesis, whereas lymphopoiesis declines [57]. It is believed that this myeloid dominance in the activity of hematopoietic stem cells (HSC) is attributable to inflammaging since it is known that inflammatory mediators enhance myeloid-biased hematopoiesis [57, 103]. In inflammatory conditions, emergency myelopoiesis can also occur in sites other than in bone marrow, e.g., in the spleen and liver; this process has been called extramedullary myelopoiesis. TGF- $\beta$ is abundantly present in hematopoietic sites but the role of TGF- $\beta$ signaling in the age-related changes still needs to be clarified. Challen et al. [104] demonstrated that TGF- $\beta 1$ was a stimulatory factor for myeloid-biased HSC proliferation and differentiation, whereas TGF- $\beta 1$ inhibited the lymphoid-biased HSC clones in mice. This indicates that TGF- $\beta$ regulates the lineage determination of HSC clones. Subsequently, Quere et al. [105] demonstrated that transcription intermediary factor $1 \gamma$ (TRIF1 $\gamma$ ), also known as tripartite motif-containing 33 (TRIM33), decreased the stability of TGFBR1 and thus suppressed TGF- $\beta$ signaling. They revealed that the myeloidbiased HSCs superimposed the responses induced by TGF- $\beta$ signaling since these clones displayed a reduced expression of TRIF $1 \gamma$ and correspondingly, there was an increased level of TGFBR1 protein. Quere et al. [105] reported that the expression of TRIF1 $\gamma$ declined in HSCs with aging which stimulated myelopoiesis. Interestingly, Flores et al. [66] revealed that there was an expansion of MDSCs with aging in mouse bone marrow. Given that MDSCs are immature myeloid cells, this emphasizes the role of TGF- $\beta$-induced myelopoiesis in the generation of immunosuppressive MDSCs in bone marrow. ECM disturbances in bone marrow with aging might also enhance the generation of MDSCs. Intriguingly, several studies have revealed that MDSCs can be differentiated into osteoclasts, both in vitro and in vivo [106, 107]. The osteoclasts derived from MDSCs are able to provoke bone resorption, e.g., in multiple myeloma [106] and collagen-induced arthritis [107]. Zoledronate, a potent inhibitor of bone resorption, was able to inhibit the expansion and differentiation of MDSCs into osteoclasts and subsequently it reduced bone lesions in myeloma-bearing mice [106]. It seems that the increased myelopoiesis associated with inflammatory changes in bone marrow induces the generation of MDSCs which enhance age-related osteoporosis (Fig. 2).

TGF- $\beta$ signaling has a crucial role in several age-related diseases, e.g., muscle atrophy [108], skin aging [109], cardiovascular diseases [110], and Alzheimer's disease [111]. Carlson et al. [112] observed that the expression of TGF- $\beta$ as well as the activation of Smad3 (pSmad3) increased with aging in mouse skeletal muscle. Particularly, the activity of Smad3 was robustly increased in myofibers. Narola et al. [113] demonstrated that the muscle-specific overexpression of TGF- $\beta 1$-induced myofiber atrophy and endomysial fibrosis in mouse skeletal muscles. In sarcopenia, TGF- $\beta$ signaling provokes fibrosis and muscle atrophy by increasing the expression of atrogin-1 and MuRF-1, E3 ubiquitin ligases, thus enhancing protein degradation [108]. TGF- $\beta$ signaling also promotes the aging process through the remodeling of the ECM in many tissues, e.g., in the aging skin [109]. Moreover, age-related changes in the ECM have a key role in vascular aging; coronary artery disease is a good example [110]. Especially, TGF- $\beta$ affects the function of smooth muscle cells in arterial aging. TGF- $\beta$ signaling controls the major risk factors for atherosclerosis, i.e., fibrosis, hyperlipidemia, hypertension, inflammation, vascular remodeling, and arterial calcification [114]. Interestingly, there are observations indicating that TGF- $\beta$ enhances the cerebral amyloid angiopathy 
in Alzheimer's disease (AD) $[111,115]$. The expression of TGF- $\beta$ was robustly increased in the brains of AD patients, especially in those microvessels that were accumulating $\beta$ amyloid proteins. In contrast, there are studies indicating that TGF- $\beta$ signaling might be impaired in AD. For instance, Baig et al. [116] demonstrated that hyperphosphorylated tau protein disturbed the signaling of $\mathrm{Smad} 2 / 3$ in neurons thus promoting $\mathrm{AD}$ pathogenesis. This controversy might reflect the contextdependency of TGF- $\beta$ responses in pathological conditions.

\section{IL-10}

The IL-10 family consists of nine members which have an important role in the regulation of tissue integrity and homeostasis by suppressing inflammation and enhancing tissue repair after injuries and infections [32]. In brief, IL-10 cytokines stimulate the signaling of STAT3 transcription factor through the receptor complex of IL-10R1 and IL-10R2 proteins. IL-10 signaling inhibits the production of inflammatory cytokines, colony-stimulating factors, and several chemokines in monocytes and macrophages. Sun et al. [117] reported that IL-10 signaling inhibited the activation of NLRP3 inflammasomes in a STAT3-dependent manner in mouse microglia. IL-10 is not only an anti-inflammatory cytokine but it also has major functions in adaptive immunity. For instance, IL-10 cytokine suppresses immune responses by inhibiting some functions of dendritic cells as well as those of T and B cells. Several studies have revealed that IL-10 signaling prevents antigen presentation by dendritic cells [118]. However, the effects of IL-10 cytokines are greatly context-dependent, e.g., within $\mathrm{T}$ cell subsets [119]. Interestingly, IL-10 cytokines are able to increase the differentiation and activity of immunosuppressive cells. For instance, Hsu et al. [120] demonstrated that IL-10 exposure increased the expression of FoxP3 protein in human $\mathrm{CD}^{+} \mathrm{T}$ cells and consequently augmented their differentiation into induced Tregs (iTreg). IL-10 treatment also increased the immunosuppressive activity of iTregs. Moreover, IL-10 cytokines have a significant role in the polarization of proinflammatory M1 macrophages towards their immunosuppressive M2 phenotypes, e.g., after mouse myocardial infarction [121]. Accordingly, immune suppressive cells, e.g., regulatory B cells (Bregs), possess a robust capacity to secrete IL10 cytokines and thus inhibit the functions of monocytes, dendritic cells, and T cells [122]. Overall, IL-10 cytokine is a significant suppressor of inflammatory responses and an important enhancer of immunosuppressive network.

IL-10 cytokines also affect other cells than simply the immune cells since IL-10RA and IL-10RB receptor proteins are expressed in a wide variety of tissues (Human Protein Atlas). IL-10 activates the STAT3 signaling which controls many regulatory functions in cytoplasm, mitochondria, and nuclei. For instance, STAT3 signaling has an important role in autophagy, both in immune and non-immune cells $[123,124]$.
There is substantial evidence that IL-10 signaling is an important inhibitor of autophagy although in some contexts, it can promote autophagy [124, 125]. For instance, IL-10 signaling inhibited the autophagy in human fibroblasts derived from hypertrophic scars [126]. Shi et al. [126] demonstrated that the crosstalk between IL-10R-STAT3 and AKT/mTOR signaling pathways promoted the inhibition of autophagy in human fibroblasts. mTOR is a well-known inhibitor of autophagy. Moreover, Kishore et al. [127] reported that IL-10 inhibited the pathological autophagy in rat ventricular cardiomyocytes induced by angiotensin II treatment. They demonstrated that IL-10 controlled autophagy via the AKT/ mTOR pathway in rat cardiomyocytes. The observation that IL-10 can prevent autophagy via the PI3K/AKT/mTOR pathway is interesting since it is known that insulin/IGF signaling inhibits autophagy through an activation of the mTOR complex which subsequently promotes the aging process [128]. However, it seems that the IL-10-induced inhibition is dependent on cell type and signaling connections since Ip et al. [125] reported that the lipopolysaccharide-induced IL-10 signaling suppressed mTOR activity and subsequently activated autophagy in human macrophages. Currently, IL-10 signaling is associated with only a few pathological processes as compared with that of TGF- $\beta$ signaling. Halvorsen et al. [129] demonstrated that IL-10 promoted the formation of the oxidized LDL-induced foam cells in human acute coronary syndrome (ACS). IL-10 signaling enhanced lipid accumulation as well as increasing the expression of anti-apoptotic genes in the macrophages isolated from ACS patients. Nakamura et al. [130] observed that the aging process robustly increased the expression of IL-10 in mouse retina and spleen. They revealed that increased STAT3 activation induced the generation of immunosuppressive M2 macrophages which promoted angiogenesis in the eyes of old mice. The targeted inhibition of IL10R's function and STAT3 signaling prevented the pathological neovascularization. Interestingly, Chakrabarty et al. [131] demonstrated that the overexpression of IL-10 in transgenic APP mice significantly augmented the deposition of $\beta$ amyloid in the hippocampus and cortex. Accordingly, the overexpression of IL-10 evoked memory impairments in transgenic APP mice. Given that IL-10R proteins are widely expressed in tissues, it is likely that the IL-10 cytokine not only affects immune cells but it also triggers bystander effects in inflamed tissues.

Immunosuppressive IL-10 cytokines mediate their transcriptional responses via the activation of STAT3 signaling, whereas TGF- $\beta$ cytokines induce their effects via the SMAD pathways (see above). It is known that both the STAT3 and SMAD factors modify the chromatin landscape in the promoter regions of their target genes $[132,133]$. Epigenetic modification either enhances the transcription of the target gene or represses its activity. The regulatory loci of $I L-10$ and $T G F-\beta$ genes are recognized as being under the epigenetic regulation 
$[134,135]$. In addition, it is known that STAT3/SMAD factors control the expression of chromatin modifiers and in that way, they can remodel the whole genome. For instance, IL-10 signaling remodels the chromatin landscape of adipose tissue to repress adipocyte thermogenesis [136]. Intriguingly, the $I L$ 10 locus can be specifically remodeled in immune cells and differentially modified in response to diverse signals [137]. TGF- $\beta$ signaling regulates cellular senescence and cardiac aging through the epigenetic regulation of chromatin landscapes [138] (Fig. 2). The remodeling of gene expression patterns by modifying chromatin loci is especially important in chronic conditions, e.g., in the aging process and age-related diseases. Recently, Benayoun et al. [40] demonstrated that the aging process induced clear alterations in the epigenomic and transcriptomic landscape of mouse and human tissues, e.g., in the heart, liver, and cerebellum. Interestingly, they observed that aging robustly upregulated the markers of many immune response pathways. Thus, it seems that epigenetic regulation is the way to control the plasticity of the immune cells during the aging process.

\section{Other cytokines}

There are several other anti-inflammatory cytokines, e.g., IL4, IL-11, IL-13, and IL-37, and many of these become enriched in certain tissues (Human Protein Atlas). However, the expression of their receptors has low tissue specificity, e.g., IL-4R and IL-11R. IL-4 and IL-13 cytokines control the JAK/STAT6 signaling through the co-operation of IL$4 \mathrm{R}$ and IL-13R. Both immune and several non-immune cells can secrete IL-4/IL-13 cytokines and furthermore they can respond to these cytokines [139]. The IL-4/IL-13 axis can induce a broad range of responses in different cells, e.g., stimulating Th2 differentiation and the M2 polarization of macrophages. Many inflammatory diseases are associated with dysfunctions in IL-4/IL-13 signaling [139]. Interestingly, IL-4 exposure can induce many alterations linked to the aging process, e.g., cardiac fibrosis [140] and cellular senescence [141]. IL-11 is an anti-inflammatory member of IL-6 cytokine family, which can activate both the JAK/STAT3 signaling and the $\mathrm{PI} 3 \mathrm{~K} / \mathrm{AKT} / \mathrm{mTOR}$ axis [142]. Given that IL-11 activates STAT3 signaling, Sumida et al. [143] demonstrated that IL11 induced the differentiation of monocytic MDSCs involving the upregulation of ARG1 and enhanced capacity to suppress T cell proliferation. Currently, the functions of tissue-enriched anti-inflammatory cytokines are poorly understood.

\section{Reactive oxygen and nitrogen species}

Immunosuppressive cells secrete reactive oxygen (ROS) and nitrogen (RNS) species with which they communicate within the immunosuppressive network and they also exploit these compounds in the suppression of effector immune cells [61,
144, 145]. NADPH oxidases (NOX), nitric oxide synthases (NOS and iNOS), and mitochondrial electron transfer chain are common sources of ROS/RNS generation in immune cells. For instance, $\mathrm{Xu}$ et al. [146] demonstrated that the ROS production by NOX1 and NOX2 induced the differentiation of mouse monocytes into macrophages and consequently enhanced their polarization into the M2 and tumorassociated macrophages (TAM), two immunosuppressive phenotypes of macrophages. Roux et al. [147] revealed that increased ROS level activated NF-KB signaling which promoted the expression of PD-L1 protein and the release of immunosuppressive chemokines in mouse and human macrophages. Moreover, it is known that the NOX-stimulated ROS production from macrophages induced the generation of Tregs in rats and humans [145]. The activation of MDSCs in different tumor models stimulated the expression of NOX2 which enhanced ROS production and $\mathrm{T}$ cell suppression [144]. Nagaraj et al. [148] reported that ROS and NO produced by mouse MDSCs nitrated the tyrosine residues of the $\mathrm{T}$ cell receptor (TCR) in $\mathrm{CD}^{+} \mathrm{T}$ cells. This nitration of the TCR prevented the antigen-specific stimulation of these cells. MDSCs can also impair the activity of NK cells and the antigen presentation of dendritic cells through the production of NO [149, 150]. Given that immunosuppressive cells generate ROS/RNS compounds, it is essential that they are protected against oxidative stress. Beury et al. [151] demonstrated that mouse MDSCs were resistant to ROS although they released an elevated level of ROS compounds. They reported that the increased expression of NRF2, a transcription factor for the antioxidant enzymes, improved the survival of MDSCs in inflamed mouse tumor conditions. The expression of NRF2 reduced the rate of apoptosis of MDSCs which increased the numbers of MDSCs in tumors. Aging and age-related diseases are associated with increased oxidative stress in tissues which might augment the activity of the immunosuppressive network and consequently enhance tissue degeneration with aging.

ROS compounds are able to control several signaling pathways by affecting protein kinases and other cell-signaling proteins [152]. One especially interesting target is the cooperation between ROS and the TGF- $\beta$-mediated processes, e.g., fibrosis, cellular senescence, and apoptosis [153, 154]. For instance, there is robust evidence that TGF- $\beta$ signaling promoted the mitochondrial and the NOX-mediated ROS generation [154]. TGF- $\beta$ stimulates mitochondrial ROS production by suppressing the expression of adenine nucleotide translocase-2 (ANT2) [155] and also reducing the activity of complex IV in the electron transfer chain [156]. Increased mitochondrial ROS generation is known to provoke cellular senescence. It seems that there exists a feed-forward mechanism since ROS stimulate the expression and activity of TGF- $\beta$ and consequently enhance the responses mediated by TGF- $\beta$ signaling in host tissues. For instance, the 
TGF- $\beta$-induced muscle atrophy is a ROS-dependent process [157] as well as that of lung fibrosis [158]. There are very few observations on the role of ROS in the control of IL-10mediated responses, e.g., ROS enhanced the responses induced by IL-10 signaling in endotoxin-induced lung inflammation in mice [159]. Interestingly, the age-related oxidative stress in host tissues might be a potent enhancer for the responses induced by TGF- $\beta$ and IL-10 signaling and thus aggravate tissue degeneration.

There is compelling evidence that the age-related lowgrade inflammation in tissues is associated with increased oxidative stress. However, currently, it is not known what is the source of ROS generation in host tissues in the inflammaging process. Moreover, as discussed above, oxidative stress can enhance the activity of immunosuppressive cells and concurrently increase the production of ROS and RNS compounds which consequently induce detrimental bystander effects in host tissues during chronic inflammation. However, ROS and RNS can have both beneficial and harmful effects in a context-dependent manner on human health and lifespan $[160,161]$. ROS and RNS compounds are very reactive molecules which can damage host tissues through the oxidative modification of a diverse set of molecules, e.g., carbonylation, S-nitrosylation, S-glutathionylation, and sulfoxidation. It seems that there is a balance between specific, physiological redox signaling and excessive, pathological reactions [162]. However, the aging process and many age-related diseases elicit an increase in the level of oxidized molecules which can provoke the accumulation of protein/lipid aggregates, e.g., lipofuscin. Notably, superoxide and NO can react with each other and generate very active peroxynitrite $\left(\mathrm{OONO}^{-}\right)$ compound. For instance, peroxynitrite can nitrate the $\mathrm{T}$ cell receptor and disturb the function of T cells [148]. Moreover, van der Loo et al. [163] reported that increased ROS generation with aging reduced NO content in rat endothelial cells through the formation of peroxynitrites, thus enhancing a process which promoted vascular aging.

On the other hand, immunosuppressive cells can downregulate the generation of $\mathrm{NO}$ which has crucial functions in cardiovascular health and diseases [36, 164]. For instance, NO controls vasodilatation through the cooperation of vascular endothelium and smooth muscles. NO also inhibits the adhesion of platelets, leukocytes, and monocytes to endothelium as well as it prevents the hyperplasia of blood vessel intima. Accordingly, disturbances in NO signaling can provoke cardiovascular disorders, e.g., hypertension and atherosclerosis. L-arginine is a shared substrate for both the NOS enzymes and ARG1 [36] which means that there exists a competition for L-arginine in inflamed tissues. Given that the increased expression of ARG1 and the subsequent depletion of L-arginine are a potent mechanism used by immunosuppressive cells to inhibit inflammation (see below), it is likely that the activation of immunosuppressive network, such as what occurs during aging [8], causes a deficiency of NO synthesis and thus elicits vascular disorders (Figs. 2 and 3). There are studies indicating that the increase in the activity of ARG1 with aging promotes vascular stiffness [165]. White et al. [166] reported that the knockdown of ARG1 restored NO signaling and improved vasodilatory effects in the aorta of old rats. Zhu et al. [167] demonstrated that the overexpression of ARG1 in human endothelial cells induced the uncoupling of eNOS and consequently increased the expression of inflammatory and senescence markers. NO deficiency might also promote the pathology of Alzheimer's disease. Austin et al. [168] reported that transgenic $\mathrm{eNOS}^{-/}$mice displayed an increased level of inflammatory markers as well as augmented the expression and processing of amyloid precursor protein (APP) in mouse hippocampus. It seems that the activation of immunosuppressive cells can disturb the balance between the activities of ARG1 and NOS enzymes and subsequently this can lead to vascular disorders.

\section{Amino acid catabolism}

Immunosuppressive cells exploit the auxotrophy of many immune cells for distinct amino acids, e.g., L-arginine and tryptophan, in the generation of immunosuppression. Auxotrophy means that cells are unable to synthesize a particular amino acid which is essential for their function. Regulatory immune cells deplete the microenvironment from these amino acids to suppress innate and adaptive immune responses [169]. However, the shortage of amino acids also induces bystander effects in neighboring cells although many cell types can activate the synthesis of the depleted amino acid. Several immunosuppressive cells express ARG1 which exhausts the L-arginine stored in the microenvironment [170]. Another immunosuppressive mechanism is the expression of indoleamine 2,3dioxygenase (IDO) which depletes tryptophan from inflamed environments [171]. It is not only the starvation of amino acids from the local microenvironment but also concurrently these regulatory immune cells generate immunomodulatory metabolites, e.g., IDO activates the kynurenine pathway [172] (Fig. 3).

\section{ARG1 and arginine metabolism}

L-arginine is a conditionally essential amino acid which is involved in pivotal functions in cellular metabolism. The ARG1-induced depletion of L-arginine from the microenvironment is a common mechanism of myeloid suppressor cells to prevent the proliferation and function of T cells which display an L-arginine auxotrophy $[169,173]$. In some myeloid suppressor cells, the activation of NOS enzymes also triggers the exhaustion of L-arginine from the milieu. For instance, MMDSCs display an increased ARG1 expression, whereas PMN-MDSCs show an elevated level of iNOS [174]. M2 
macrophages display an increased expression of ARG1 but show a negligible expression of iNOS. L-arginine depletion mainly affects the cells which express L-arginine auxotrophy. However, the expression of argininosuccinate synthetase (ASS), catalyzing the de novo synthesis of L-arginine, seems to be very low in many tissues (Human Protein Atlas). This means that the deprivation of L-arginine might not only affect L-arginine-deficient immune cells but also disturb the functions of neighboring cells. Interestingly, there are some tumor types which are dependent on extracellular L-arginine since they do not express ASS [175]. ARG1 and NOS enzymes are not only catabolic enzymes which can process/compete from the tissue pool of L-arginine. Arginine decarboxylase generates agmatine which subsequently can be metabolized to urea and polyamines. Agmatine has many neuroprotective effects [176]. The activation of ARG1 and iNOS most probably impairs the generation of agmatine in inflamed tissues. The most important L-arginine catabolic pathways are the arginine/NO pathway and the arginine/ornithine pathway [36]. The effects of NO on the health of host tissues were discussed above. The activation of ARG1 produces ornithine and consequently common polyamines, i.e., putrescine, spermidine, and spermine. Polyamines exert many beneficial effects on both immune cells and host tissues. For instance, spermidine increases autophagy and thus it has important cardioprotective and neuroprotective effects [177]. However, the increased level of polyamines has many pathological effects, e.g., on cancer progression and neurological diseases [178]. For instance, the catabolism of polyamines generates ROS compounds which might have an important role in the generation of immunosuppression but oxidative stress commonly exerts detrimental effects on the host tissues. Currently, it is not known whether polyamines induce immunosuppression although there are studies indicating that polyamineblocking therapy might reverse immunosuppressive conditions, e.g., by reducing the level of MDSCs and increasing the numbers of $\mathrm{CD}^{+} \mathrm{T}$ cells, in a tumor microenvironment in mice [179].

The maintenance of tissue amino acid homeostasis has a crucial role for the growth, metabolism, and survival of organism. There are two major sensor mechanisms which assess the balance of amino acids in tissues, i.e., the mechanistic target of rapamycin complex 1 (mTORC1) and general control nonderepressible 2 (GCN2) (Fig. 3). The GCN2 kinase is activated by amino acid deprivation and it is linked to the regulation of eIF $2 \alpha$-driven protein synthesis and gene expression (see below). mTORC1 is the nutrient-sensing protein kinase which regulates both the growth and metabolism in eukaryotes [180]. The mTORC1 complex acts as a sensor for the cellular availability of arginine, leucine, and methionine through different mechanisms. Chantranupong et al. [181] demonstrated that the CASTOR1 protein detected the presence of arginine in the cytoplasm of mammalian cells.
The binding of arginine to the CASTOR1 protein stimulated downstream mTORC1 kinase through the GATORRagGTPase complex at the lysosomal surface. The deprivation of arginine prevented the activation of mTORC1 kinase. Moreover, the SLC38A9 protein, an arginine sensor in the lysosomal compartment, activates mTORC1 kinase and also acts as the arginine-dependent transporter of essential amino acids from lysosomes [182]. This means that arginine is the fundamental regulator of mTORC1 activity and thus it controls protein synthesis and diverse metabolic responses in mammalian cells. Interestingly, there is substantial evidence that the nutrient-sensing mTORC1 pathway has a key role in the regulation of aging and longevity [183]. It is known that dietary restriction linked to reduced amino acid intake extends health span and longevity; this phenomenon is evident from yeast to humans [184]. In fact, the increased activity of mTORC1 reduces lifespan, whereas the reduced activity of mTORC1, i.e., amino acid shortage, increases health span and longevity. There is abundant evidence indicating that protein synthesis is reduced with aging [185]. Correspondingly, protein turnover time is extended, especially due to a slowing of autophagy, which means that cellular protein quality control deteriorates with aging. Currently, it is very likely that the deprivation of arginine exerts bystander effects on the activity of mTORC1 kinase in inflamed microenvironments.

\section{IDO and kynurenine signaling}

IDO is the rate-limiting enzyme in the kynurenine pathway which catabolizes tryptophan, an essential amino acid, to kynurenine and a number of intermediate metabolites. Ultimately, these metabolites can be processed to nicotinamide adenine dinucleotide (NAD) [37, 172]. The inflammatory mediators are the potent inducers of IDO expression, especially IFN- $\gamma$ and TGF- $\beta$. IDO has not only been expressed in immunoregulatory cells but many non-immune cells display the expression of IDO, e.g., many cancer cells. The activation of IDO in inflamed tissue induces a robust immunosuppressive response [34, 186]. For instance, Holmgaard et al. [186] demonstrated that the expression of IDO in human and mouse tumors induced the recruitment, expansion, and activation of MDSCs in tumor sites. They observed that the activation of MDSCs was dependent on the presence of Fox $3^{+}$-positive Tregs. Recently, Ladomersky et al. [187] reported that the age-related decrease in the efficacy of immunotherapy against mouse glioblastoma was associated with an increase in the expression of IDO protein with aging in mouse brain. However, the age-related immunosuppression was not reversed by the treatment with the pharmacological inhibitor of IDO enzyme. Interestingly, Mezrich et al. [188] demonstrated that kynurenine, the first metabolite of tryptophan degradation, activated aryl hydrocarbon receptor (AhR) signaling. The activation of AhR, a 
transcription factor, induced the differentiation of mouse $\mathrm{CD}^{+}{ }^{+} \mathrm{T}$ cells into the immunosuppressive FoxP $3^{+}$Tregs. They also revealed that TGF- $\beta$ stimulated the expression of AhR and accordingly, the activation of AhR stimulated the IDO expression in mouse dendritic cells. MDSCs and Tregs display an elevated expression of IDO which enhances immunosuppression in inflamed tissues by activating the function of the immunosuppressive network.

The activation of IDO induces the deprivation of tryptophan in inflamed tissues (Fig. 3). The deficiency of this amino acid stimulates GCN2 kinase through the accumulation of uncharged tRNAs into the cell [189]. GCN2 phosphorylates the eukaryotic initiation factor $2 \alpha$ (eIF2 $\alpha$ ) which consequently inhibits protein synthesis. Given that tryptophan is an essential amino acid, it is expected that the activation of IDO as well as the tryptophan transporters in immunosuppressive cells can induce a tryptophan depletion in inflamed tissue which leads to an inhibition of protein synthesis in nearby non-immune cells. Clear tissue atrophy is evident not only in aged tissues but also in many age-related diseases, e.g., Alzheimer's disease [190]. The activation of GCN2 also controls gene expression since phospho-eIF $2 \alpha$ stimulates the activating transcription factor 4 (ATF4) [191]. The activation of ATF 4 can cause many pathological effects in tissues although it is able to increase cellular survival during stressful situations. For instance, the activation of ATF4 can promote skeletal muscle atrophy [192], atherosclerotic calcification of vascular smooth muscles [193], and neurodegenerative diseases [194]. There are several studies indicating that the increased activity of eIF $2 \alpha /$ ATF 4 signaling exerts detrimental effects in Alzheimer's pathology, e.g., it increases the generation of $\beta$ amyloid peptides and tau-protein phosphorylation [195]. On the other hand, there is an abundant literature that the deficiency of essential amino acids, especially that of tryptophan and methionine, can increase the lifespan of several species, e.g., mammals [196]. Currently, the detailed mechanism is still unknown although it is known that the activation of ATF4 via GCN2 stimulates integrated stress response (ISR) which increases the stress resistance of the organism [197] (Fig. 3).

The inflammation-induced activation of IDO in immune cells generates kynurenine and its metabolites which affect the functions of neighboring cells. In addition to beneficial effects, e.g., blood vessel dilatation, kynurenines are involved in a number of pathological processes, e.g., cardiovascular diseases [198], neurodegenerative diseases [199], muscle atrophy [200], and osteoporosis [201]. There are observations that kynurenines might have a significant role in the inflammaging process, e.g., in the control of inflammatory responses [202]. Moreover, Guillemin et al. [203] reported that the expression of IDO and the production of the excitotoxic compound, quinolinic acid, which is a metabolite of the kynurenine pathway, were robustly increased in the hippocampus of $\mathrm{AD}$ patients. The pathological mechanisms induced by kynurenines are poorly understood. It is known that the kynurenine pathway and its metabolites affect the redox pathways and energy metabolism [204, 205]. Wang et al. [206] demonstrated that tryptophan-derived 3hydroxykynurenine stimulated the activity of NADPH oxidase (NOX) and increased superoxide production inducing dysfunctions and apoptosis in mouse endothelial cells. Kynurenine also inhibited autophagy and promoted senescence, e.g., in the mesenchymal stem cells isolated from the bone marrow of old mice [207]. Given that serotonin is synthesized from tryptophan, the depletion of tryptophan in chronic inflammation can provoke metabolic, psychiatric, and gastrointestinal disorders [208]. It seems that the function of IDO not only induces immunosuppression via the tryptophan catabolism but the breakdown of tryptophan through the kynurenine pathway triggers many of the pathological processes commonly observed during aging although causality needs to be clarified.

\section{Conclusions}

\section{Is immunosuppression the driving force in the aging process?}

There is convincing evidence that chronic low-grade inflammation is associated with the aging process in many different species. Concurrently with inflammatory changes, the signs of senescence, i.e., a state called immunosenescence, appear in the immune system. Currently, it is not known whether the remodeling of the immune system associated with aging is the cause or consequence of the chronic inflammation. The origin of age-related inflammation still needs to be clarified although there are several possible sources. Chronic inflammation is commonly associated with the compensatory immunosuppressive response. There is substantial evidence that immunosuppression increases with aging [8]. Interestingly, the hallmarks of immunosenescence are similar to those induced by immunosuppressive MDSCs, e.g., (i) a decline in the functions of $\mathrm{T}$ and $\mathrm{B}$ cells, (ii) a decrease in antigen presentation by dendritic cells, and (iii) the inhibition of cytotoxicity of NK cells [209]. Given the close cooperation between the immune cells within the immunosuppressive network, it seems likely that age-related chronic inflammation activates the immunosuppressive network which remodels the immune system with aging promoting immunosenescence with many harmful effects, e.g., increased risk for cancers, enhanced vulnerability to infections, and decreased vaccination efficacy. However, the activation of immunosuppressive network keeps proinflammatory cells under control, thus preventing tissue damage induced by persistent inflammation.

The armament of immunosuppressive cells utilizes both the targeted and non-targeted mechanisms to suppress the activity 
of effector immune cells. Immunosuppressive cells, e.g., MDSCs and Tregs, exploit the contact-dependent immune checkpoint receptors, such as PD-L1/PD-1 and CTLA-4 systems, to inhibit the function of immune cells [210]. However, the majority of the weapons are soluble tools, e.g., TGF- $\beta$ and IL-10 cytokines and ROS, as well as alterations in the catabolism of arginine and tryptophan in inflammatory conditions. These non-targeted mechanisms also affect the neighboring cells in distressed tissues and provoke degenerative changes if the inflammation becomes chronic. For instance, the receptors of TGF- $\beta$ and IL-10 are widely expressed in non-immune cells and especially TGF- $\beta$ signaling can trigger many agerelated degenerative changes, e.g., cellular senescence, fibrosis, osteoporosis, and ECM disruption. Moreover, the secretion of toxic ROS/RNS compounds damage host tissues in chronic inflammation. Immunosuppressive cells also exploit amino acid catabolism which has direct effects on the nearby cells via the depletion of amino acids, e.g., the shortage of tryptophan, an essential amino acid, might enhance atrophic degeneration in inflamed tissues. The ARG1-induced deprivation of NO might enhance vascular aging, whereas the IDOinduced kynurenine metabolites are able extensively to disturb tissue homeostasis. In conclusion, the age-related low-grade inflammation activates compensatory immunosuppression which not only triggers immunosenescence but also disturbs tissue homeostasis, thus enhancing tissue degeneration with aging.

Acknowledgments The author thanks Dr. Ewen MacDonald for checking the language of the manuscript.

Authors' contributions This research in a sole work by the author.

Funding Open access funding provided by University of Eastern Finland (UEF) including Kuopio University Hospital.

Availability of data and materials Not applicable

\section{Compliance with ethical standards}

Ethics approval This research has full compliance with ethical standards as pertinent to review article.

\section{Consent for publication Not applicable}

Competing interests The author declares that he has no conflict of interest.

Open Access This article is licensed under a Creative Commons Attribution 4.0 International License, which permits use, sharing, adaptation, distribution and reproduction in any medium or format, as long as you give appropriate credit to the original author(s) and the source, provide a link to the Creative Commons licence, and indicate if changes were made. The images or other third party material in this article are included in the article's Creative Commons licence, unless indicated otherwise in a credit line to the material. If material is not included in the article's Creative Commons licence and your intended use is not permitted by statutory regulation or exceeds the permitted use, you will need to obtain permission directly from the copyright holder. To view a copy of this licence, visit http://creativecommons.org/licenses/by/4.0/.

\section{References}

1. Franceschi C, Bonafe M, Valensin S, Olivieri F, De Luca M, Ottaviani E, De Benedictis G (2000) Inflamm-aging. An evolutionary perspective on immunosenescence. Ann N Y Acad Sci 908:244-254

2. Fulop T, Larbi A, Witkowski JM (2019) Human inflammaging. Gerontology 65:495-504

3. Furman D, Campisi J, Verdin E, Carrera-Bastos P, Targ S, Franceschi C, Ferrucci L, Gilroy DW, Fasano A, Miller GW, Miller AH, Mantovani A, Weyand CM, Barzilai N, Goronzy JJ, Rando TA, Effros RB, Lucia A, Kleinstreuer N, Slavich GM (2019) Chronic inflammation in the etiology of disease across the life span. Nat Med 25:1822-18323

4. Kanterman J, Sade-Feldman M, Baniyash M (2012) New insights into chronic inflammation-induced immunosuppression. Semin Cancer Biol 22:307-318

5. Mira JC, Brakenridge SC, Moldawer LL, Moore FA (2017) Persistent inflammation, immunosuppression and catabolism syndrome. Crit Care Clin 33:245-258

6. Franceschi C, Capri M, Monti D, Giunta S, Olivieri F, Sevini F, Panourgia MP, Invidia L, Celani L, Scurti M, Cevenini E, Castellani GC, Salvioli S (2007) Inflammaging and antiinflammaging: a systemic perspective on aging and longevity emerged from studies in humans. Mech Ageing Dev 128:92-105

7. Minciullo PL, Catalano A, Mandraffino G, Casciaro M, Crucitti A, Maltese G, Morabito N, Lasco A, Gangemi S, Basile G (2016) Inflammaging and anti-inflammaging: the role of cytokines in extreme longevity. Arch Immunol Ther Exp 64:111-126

8. Salminen A (2020) Activation of immunosuppressive network in the aging process. Ageing Res Rev 57:100998

9. Goronzy JJ, Weyand CM (2006) Immunosuppression in atherosclerosis: mobilizing the opposition within. Circulation 114:19011904

10. Yao L, Abe M, Kawasaki K, Akbar SM, Matsuura B, Onji M, Hiasa Y (2016) Characterization of liver monocytic myeloidderived suppressor cells and their role in a murine model of nonalcoholic fatty liver disease. PLoS One 11:e0149948

11. Balk RA (2014) Systemic inflammatory response syndrome (SIRS): where did it come from and is it still relevant today? Virulence 5:20-26

12. Gentile LF, Cuenca AG, Efron PA, Ang D, Bihorac A, McKinley BA, Moldawer LL, Moore FA (2012) Persistent inflammation and immunosuppression: a common syndrome and new horizon for surgical intensive care. J Trauma Acute Care Surg 72:1491-1501

13. Brudecki L, Ferguson DA, McCall CE, El Gazzar M (2012) Myeloid-derived suppressor cells evolve during sepsis and can enhance or attenuate the systemic inflammatory response. Infect Immun 80:2026-2034

14. Cuenca AG, Delano MJ, Kelly-Scumpia KM, Moreno C, Scumpia PO, Laface DM, Heyworth PG, Efron PA, Moldawer LL (2011) A paradoxical role for myeloid-derived suppressor cells in sepsis and trauma. Mol Med 17:281-292

15. Gabrilovich DI, Nagaraj S (2009) Myeloid-derived suppressor cells as regulators of the immune system. Nat Rev Immunol 9: $162-174$ 
16. Wang D, DuBois RN (2015) Immunosuppression associated with chronic inflammation in the tumor microenvironment. Carcinogenesis 36:1085-1093

17. Amodio G, Cichy J, Conde P, Matteoli G, Moreau A, Ochando J, Oral BH, Pekarova M, Ryan EJ, Roth J, Sohrabi Y, Cuturi MC, Gregori S (2019) Role of myeloid regulatory cells (MRCs) in maintaining tissue homeostasis and promoting tolerance in autoimmunity, inflammatory disease and transplantation. Cancer Immunol Immunother 68:661-672

18. Kuilman T, Michaloglou C, Vredeveld LC, Douma S, van Doorn R, Desmet CJ, Aarden LA, Mooi WJ, Peeper DS (2008) Oncogene-induced senescence relayed by an interleukindependent inflammatory network. Cell 133:1019-1031

19. Freund A, Orjalo AV, Desprez PY, Campisi J (2010) Inflammatory networks during cellular senescence: causes and consequences. Trends Mol Med 16:238-246

20. Ruhland MK, Loza AJ, Capietto AH, Luo X, Knolhoff BL, Flanagan KC, Belt BA, Alspach E, Leahy K, Luo J, Schaffer A, Edwards JR, Longmore G, Faccio R, DeNardo DG, Stewart SA (2016) Stromal senescence establishes an immunosuppressive microenvironment that drives tumorigenesis. Nat Commun 7:11762

21. Murray PJ (2017) Macrophage polarization. Annu Rev Physiol 79:541-566

22. Mantovani A, Marchesi F, Malesci A, Laghi L, Allavena P (2017) Tumour-associated macrophages as treatment targets in oncology. Nat Rev Clin Oncol 14:399-416

23. Dixon KO, Rossmann L, Kamerling SW, van Kooten C (2014) Human renal fibroblasts generate dendritic cells with a unique regulatory profile. Immunol Cell Biol 92:688-698

24. Klicznik MM, Szenes-Nagy AB, Campbell DJ, Gratz IK (2018) Taking the lead - how keratinocytes orchestrate skin T cell immunity. Immunol Lett 200:43-51

25. Sorokin L (2010) The impact of the extracellular matrix on inflammation. Nat Rev Immunol 10:712-723

26. Umansky V, Adema GJ, Baran J, Brandau S, Van Ginderachter JA, Hu X, Jablonska J, Mojsilovic S, Papadaki HA, Pico de Coana Y, Santegoets KCM, Santibanez JF, Serre K, Si Y, Sieminska I, Velegraki M, Fridlender ZG (2019) Interactions among myeloid regulatory cells in cancer. Cancer Immunol Immunother 68:645660

27. Shevach EM, Thornton AM (2014) tTregs, pTregs, and iTregs: similarities and differences. Immunol Rev 259:88-102

28. Mauri C, Menon M (2015) The expanding family of regulatory B cells. Int Immunol 27:479-486

29. Park MJ, Lee SH, Kim EK, Lee EJ, Park SH, Kwok SK, Cho ML (2016) Myeloid-derived suppressor cells induce the expansion of regulatory B cells and ameliorate autoimmunity in the Sanroque mouse model of systemic lupus erythematosus. Arthritis Rheum 68:2717-2727

30. Olkhanud PB, Damdinsuren B, Bodogai M, Gress RE, Sen R, Wejksza K, Malchinkhuu E, Wersto RP, Biragyn A (2011) Tumor-evoked regulatory B cells promote breast cancer metastasis by converting resting $\mathrm{CD}^{+} \mathrm{T}$ cells to T-regulatory cells. Cancer Res 71:3505-3515

31. Li MO, Wan YY, Sanjabi S, Robertson AK, Flavell RA (2006) Transforming growth factor- $\beta$ regulation of immune responses. Annu Rev Immunol 24:99-146

32. Ouyang W, Rutz S, Crellin NK, Valdez PA, Hymowitz SG (2011) Regulation and functions of the IL-10 family of cytokines in inflammation and disease. Annu Rev Immunol 29:71-109

33. Palomares O, Martin-Fontecha M, Lauener R, Traidl-Hoffmann C, Cavkaytar O, Akdis M, Akdis CA (2014) Regulatory T cells and immune regulation of allergic diseases: roles of IL-10 and TGF- $\beta$. Genes Immun 15:511-520

34. McGaha TL, Huang L, Lemos H, Metz R, Mautino M, Prendergast GC, Mellor AL (2012) Amino acid catabolism: a pivotal regulator of innate and adaptive immunity. Immunol Rev 249:135-157

35. Mondanelli G, Ugel S, Grohmann U, Bronte V (2017) The immune regulation in cancer by the amino acid metabolizing enzymes ARG and IDO. Curr Opin Pharmacol 35:30-39

36. Rath M, Müller I, Kropf P, Closs EI, Munder M (2014) Metabolism via arginase or nitric oxide synthase: two competing arginine pathways in macrophages. Front Immunol 5:532

37. Chen Y, Guillemin GJ (2009) Kynurenine pathway metabolites in humans: disease and healthy states. Int J Tryptophan Res 2:11938

38. Hernandez-Segura A, Nehme J, Demaria M (2018) Hallmarks of cellular senescence. Trends Cell Biol 28:436-453

39. Coppe JP, Desprez PY, Krtolica A, Campisi J (2010) The senescence-associated secretory phenotype: the dark side of tumor suppression. Annu Rev Pathol 5:99-118

40. Benayoun BA, Pollina EA, Singh PP, Mahmoudi S, Harel I, Casey KM, Dulken BW, Kundaje A, Brunet A (2019) Remodeling of epigenome and transcriptome landscapes with aging in mice reveals widespread induction of inflammatory responses. Genome Res 29:697-709

41. Terlecki-Zaniewicz L, Lämmermann I, Latreille J, Bobbili MR, Pils V, Schosserer M, Weinmüllner R, Dellago H, Skalicky S, Pum D, Almaraz JCH, Scheideler M, Morizot F, Hackl M, Gruber F, Grillari J (2018) Small extracellular vesicles and their miRNA cargo are anti-apoptotic members of the senescenceassociated secretory phenotype. Aging (Albany NY) 10:11031132

42. Riquelme JA, Takov K, Santiago-Fernandez C, Rossello X, Lavandero S, Yellon DM, Davidson SM (2020) Increased production of functional small extracellular vesicles in senescent endothelial cells. J Cell Mol Med 24:4871-4876

43. Krishnamurthy J, Torrice C, Ramsey MR, Kovalev GI, AlRegaiey K, Su L, Sharpless NE (2004) Ink4a/Arf expression is a biomarker of aging. J Clin Invest 114:1299-1307

44. Biran A, Zada L, Abou Karam P, Vadai E, Roitman L, Ovadya Y, Porat Z, Krizhanovsky V (2017) Quantitative identification of senescent cells in aging and disease. Aging Cell 16:661-671

45. Ogrodnik M, Miwa S, Tchkonia T, Tiniakos D, Wilson CL, Lahat A, Day CP, Burt A, Palmer A, Anstee QM, Grellscheid SN, Hoeijmakers JHJ, Barnhoorn S, Mann DA, Bird TG, Vermeij WP, Kirkland JL, Passos JF, von Zglinicki T, Jurk D (2017) Cellular senescence drives age-dependent hepatic steatosis. Nat Commun 8:15691

46. Olivieri F, Recchioni R, Marcheselli F, Abbatecola AM, Santini G, Borghetti G, Antonicelli R, Procopio AD (2013) Cellular senescence in cardiovascular diseases: potential age-related mechanisms and implications for treatment. Curr Pharm Des 19:1710 1719

47. Nelson G, Wordsworth J, Wang C, Jurk D, Lawless C, MartinRuiz C, von Zglinicki T (2012) A senescent cell bystander effect: senescence-induced senescence. Aging Cell 11:345-349

48. da Silva PFL, Ogrodnik M, Kucheryavenko O, Glibert J, Miwa S, Cameron K, Ishaq A, Saretzki G, Nagaraja-Grellscheid S, Nelson G, von Zglinicki T (2019) The bystander effect contributes to the accumulation of senescent cells in vivo. Aging Cell 18:12848

49. Mensa E, Guescini M, Giuliani A, Bacalini MG, Ramini D, Corleone G, Ferracin M, Fulgenzi G, Graciotti L, Prattichizzo F, Sorci L, Battistelli M, Monsurro V, Bonfigli AR, Cardelli M, Recchioni R, Marcheselli F, Latini S, Maggio S, Fanelli M, Amatori S, Storci G, Ceriello A, Stocchi V, De Luca M, Magnani L, Rippo MR, Procopio AD, Sala C, Budimir I, Bassi C, Negrini M, Garagnani P, Franceschi C, Sabbatinelli J, Bonafe M, Olivieri F (2020) Small extracellular vesicles deliver miR-21 and miR-217 as pro-senescence effectors to endothelial cells. J Extracell Vesicles 9:1725285 
50. Acosta JC, Banito A, Wuestefeld T, Georgilis A, Janich P, Morton JP, Athineos D, Kang TW, Lasitschka F, Andrulis M, Pascual G, Morris KJ, Khan S, Jin H, Dharmalingam G, Snijders AP, Carroll T, Capper D, Pritchard C, Inman GJ, Longerich T, Sansom OJ, Benitah SA, Zender L, Gil J (2013) A complex secretory program orchestrated by the inflammasome controls paracrine senescence. Nat Cell Biol 15:978-990

51. Sagiv A, Burton DG, Moshayev Z, Vadai E, Wensveen F, BenDor S, Golani O, Polic B, Krizhanovsky V (2016) NKG2D ligands mediate immunosurveillance of senescent cells. Aging (Albany NY) 8:328-344

52. Ghiringhelli F, Menard C, Martin F, Zitvogel L (2006) The role of regulatory $\mathrm{T}$ cells in the control of natural killer cells: relevance during tumor progression. Immunol Rev 214:229-238

53. Li H, Han Y, Guo Q, Zhang M, Cao X (2009) Cancer-expanded myeloid-derived suppressor cells induce anergy of NK cells through membrane-bound TGF- $\beta$ 1. J Immunol 182:240-249

54. Wiley CD, Velarde MC, Lecot P, Liu S, Sarnoski EA, Freund A, Shirakawa K, Lim HW, Davis SS, Ramanathan A, Gerencser AA, Verdin E, Campisi J (2016) Mitochondrial dysfunction induces senescence with a distinct secretory phenotype. Cell Metab 23: 303-314

55. Park MY, Lim BG, Kim SY, Sohn HJ, Kim S, Kim TG (2019) GM-CSF promotes the expansion and differentiation of cord blood myeloid-derived suppressor cells, which attenuate xenogeneic graft-vs.-host disease. Front Immunol 10:183

56. Hotta M, Yoshimura H, Satake A, Tsubokura Y, Ito T, Nomura S (2019) GM-CSF therapy inhibits chronic graft-versus-host disease via expansion of regulatory T cells. Eur J Immunol 49:179-191

57. Pang WW, Price EA, Sahoo D, Beerman I, Maloney WJ, Rossi DJ, Schrier SL, Weissman IL (2011) Human bone marrow hematopoietic stem cells are increased in frequency and myeloid-biased with age. Proc Natl Acad Sci U S A 108:20012-20017

58. Condamine T, Gabrilovich DI (2011) Molecular mechanisms regulating myeloid-derived suppressor cell differentiation and function. Trends Immunol 32:19-25

59. Oh H, Grinberg-Bleyer Y, Liao W, Maloney D, Wang P, Wu Z, Wang J, Bhatt DM, Heise N, Schmid RM, Hayden MS, Klein U, Rabadan R, Ghosh S (2017) An NF-kB transcription-factordependent lineage-specific transcriptional program promotes regulatory $\mathrm{T}$ cell identity and function. Immunity 47:450-465

60. Corzo CA, Condamine T, Lu L, Cotter MJ, Youn JI, Cheng P, Cho HI, Celis E, Quiceno DG, Padhya T, McCaffrey TV, McCaffrey JC, Gabrilovich DI (2010) HIF-1 $\alpha$ regulates function and differentiation of myeloid-derived suppressor cells in the tumor microenvironment. J Exp Med 207:2439-2453

61. Ohl K, Tenbrock K (2018) Reactive oxygen species as regulators of MDSC-mediated immune suppression. Front Immunol 9:2499

62. Salminen A, Kaarniranta K, Kauppinen A (2020) ER stress activates immunosuppressive network: implications for aging and Alzheimer's disease. J Mol Med (Berl) 98:633-650

63. Ben-Meir K, Twaik N, Baniyash M (2018) Plasticity and biological diversity of myeloid derived suppressor cells. Curr Opin Immunol 51:154-161

64. Enioutina EY, Bareyan D, Daynes RA (2011) A role for immature myeloid cells in immune senescence. J Immunol 186:697-707

65. Verschoor CP, Johnstone J, Millar J, Dorrington MG, Habibagahi M, Lelic A, Loeb M, Bramson JL, Bowdish DM (2013) Blood CD33+HLA-DR- myeloid-derived suppressor cells are increased with age and a history of cancer. J Leukoc Biol 93:633-637

66. Flores RR, Clauson CL, Cho J, Lee BC, McGowan SJ, Baker DJ, Niedernhofer LJ, Robbins PD (2017) Expansion of myeloidderived suppressor cells with aging in the bone marrow of mice through a NF-kB-dependent mechanism. Aging Cell 16:480-487

67. Lages CS, Suffia I, Velilla PA, Huang B, Warshaw G, Hildeman DA, Belkaid Y, Chougnet C (2008) Functional regulatory T cells accumulate in aged hosts and promote chronic infectious disease reactivation. J Immunol 181:1835-1848

68. Garg SK, Delaney C, Toubai T, Ghosh A, Reddy P, Banerjee R, Yung R (2014) Aging is associated with increased regulatory Tcell function. Aging Cell 13:441-448

69. Bapat SP, Myoung Suh J, Fang S, Liu S, Zhang Y, Cheng A, Zhou C, Liang Y, LeBlanc M, Liddle C, Atkins AR, Yu RT, Downes M, Evans RM, Zheng Y (2015) Depletion of fat-resident Treg cells prevents age-associated insulin resistance. Nature 528:137-141

70. Jackaman C, Radley-Crabb HG, Soffe Z, Shavlakadze T, Grounds MD, Nelson DJ (2013) Targeting macrophages rescues agerelated immune deficiencies in $\mathrm{C} 57 \mathrm{BL} / 6 \mathrm{~J}$ geriatric mice. Aging Cell 12:345-357

71. Wang Y, Wehling-Henricks M, Samengo G, Tidball JG (2015) Increases of M2a macrophages and fibrosis in aging muscle are influenced by bone marrow aging and negatively regulated by muscle-derived nitric oxide. Aging Cell 14:678-688

72. Worthington JJ, Klementowicz JE, Travis MA (2011) TGF $\beta$ : a sleeping giant awoken by integrins. Trends Biochem Sci 36:47-54

73. Flavell RA, Sanjabi S, Wrzesinski SH, Licona-Limon P (2010) The polarization of immune cells in the tumour environment by TGF $\beta$. Nat Rev Immunol 10:554-567

74. David CJ, Massague J (2018) Contextual determinants of TGF $\beta$ action in development, immunity and cancer. Nat Rev Mol Cell Biol 19:419-435

75. Zhang Y, Alexander PB, Wang XF (2017) TGF- $\beta$ family signaling in the control of cell proliferation and survival. Cold Spring Harb Perspect Biol 9:a022145

76. Tominaga K, Suzuki HI (2019) TGF- $\beta$ signaling in cellular senescence and aging-related pathology. Int J Mol Sci 20:5002

77. Vijayachandra K, Higgins W, Lee J, Glick A (2009) Induction of p16ink4a and p19ARF by TGF $\beta 1$ contributes to growth arrest and senescence response in mouse keratinocytes. Mol Carcinog 48: 181-186

78. Rapisarda V, Borghesan M, Miguela V, Encheva V, Snijders AP, Lujambio A, O'Loghlen A (2017) Integrin $\beta 3$ regulates cellular senescence by activating the TGF- $\beta$ pathway. Cell Rep 18:2480 2493

79. Salminen A, Kauppinen A, Kaarniranta K (2012) Emerging role of NF-KB signaling in the induction of senescence-associated secretory phenotype (SASP). Cell Signal 24:835-845

80. Salminen A, Kauppinen A, Kaarniranta K (2018) Myeloidderived suppressor cells (MDSC): an important partner in cellular/tissue senescence. Biogerontology 19:325-339

81. van der Kraan PM (2017) The changing role of TGF $\beta$ in healthy, ageing and osteoarthritic joints. Nat Rev Rheumatol 13:155-163

82. Munoz-Espin D, Serrano M (2014) Cellular senescence: from physiology to pathology. Nat Rev Mol Cell Biol 15:482-496

83. Baker DJ, Childs BG, Durik M, Wijers ME, Sieben CJ, Zhong J, Saltness RA, Jeganathan KB, Verzosa GC, Pezeshki A, Khazaie K, Miller JD, van Deursen JM (2016) Naturally occurring p16(Ink4a)-positive cells shorten healthy lifespan. Nature 530: 184-189

84. Meng XM, Nikolic-Paterson DJ, Lan HY (2016) TGF- $\beta$ : the master regulator of fibrosis. Nat Rev Nephrol 12:325-338

85. Wynn TA (2008) Cellular and molecular mechanisms of fibrosis. J Pathol 214:199-210

86. Tang PM, Nikolic-Paterson DJ, Lan HY (2019) Macrophages: versatile players in renal inflammation and fibrosis. Nat Rev Nephrol 15:144-158

87. Lebrun A, Lo Re S, Chantry M, Izquierdo Carerra X, Uwambayinema F, Ricci D, Devosse R, Ibouraadaten S, Brombin L, Palmai-Pallag M, Yakoub Y, Pasparakis M, Lison D, Huaux F (2017) CCR2 ${ }^{+}$monocytic myeloid-derived suppressor cells (M-MDSCs) inhibit collagen degradation and promote 
lung fibrosis by producing transforming growth factor- $\beta 1$. J Pathol 243:320-330

88. Chakraborty K, Chatterjee S, Bhattacharyya A (2018) Impact of Treg on other $\mathrm{T}$ cell subsets in progression of fibrosis in experimental lung fibrosis. Tissue Cell 53:87-92

89. Doi S, Zou Y, Togao O, Pastor JV, John GB, Wang L, Shiizaki K, Gotschall R, Schiavi S, Yorioka N, Takahashi M, Boothman DA, Kuro-o M (2011) Klotho inhibits transforming growth factor- $\beta 1$ (TGF- $\beta 1$ ) signaling and suppresses renal fibrosis and cancer metastasis in mice. J Biol Chem 286:8655-8665

90. Lim JY, Oh MA, Kim WH, Sohn HY, Park SI (2012) AMPactivated protein kinase inhibits TGF- $\beta$-induced fibrogenic responses of hepatic stellate cells by targeting transcriptional coactivator p300. J Cell Physiol 227:1081-1089

91. Mencke R, Hillebrands JL, NIGRAM consortium (2017) The role of the anti-ageing protein Klotho in vascular physiology and pathophysiology. Ageing Res Rev 35:124-146

92. Munger JS, Sheppard D (2011) Cross talk among TGF- $\beta$ signaling pathways, integrins, and the extracellular matrix. Cold Spring Harb Perspect Biol 3:a005017

93. Han YP, Tuan TL, Hughes M, Wu H, Garner WL (2001) Transforming growth factor- $\beta$ - and tumor necrosis factor- $\alpha$-mediated induction and proteolytic activation of MMP-9 in human skin. J Biol Chem 276:22341-22350

94. Kim HS, Shang T, Chen Z, Pflugfelder SC, Li DQ (2004) TGF- $\beta 1$ stimulates production of gelatinase (MMP-9), collagenases (MMP-1, -13) and stromelysins (MMP-3, -10, -11) by human corneal epithelial cells. Exp Eye Res 79:263-274

95. Toba H, Cannon PL, Yabluchanskiy A, Iyer RP, D'Armiento J, Lindsey ML (2017) Transgenic overexpression of macrophage matrix metalloproteinase- 9 exacerbates age-related cardiac hypertrophy, vessel rarefaction, inflammation, and fibrosis. Am J Physiol Heart Circ Physiol 12:H375-H383

96. Frevert CW, Felgenhauer J, Wygrecka M, Nastase MV, Schaefer L (2018) Danger-associated molecular patterns derived from the extracellular matrix provide temporal control of innate immunity. J Histochem Cytochem 66:213-227

97. Shao L, Zhang B, Wang L, Wu L, Kan Q, Fan K (2017) MMP-9cleaved osteopontin isoform mediates tumor immune escape by inducing expansion of myeloid-derived suppressor cells. Biochem Biophys Res Commun 493:1478-1484

98. Le Page A, Khalil A, Vermette P, Frost EH, Larbi A, Witkowski JM, Fulop T (2019) The role of elastin-derived peptides in human physiology and diseases. Matrix Biol 84:81-96

99. Huleihel L, Dziki JL, Bartolacci JG, Rausch T, Scarritt ME, Cramer MC, Vorobyov T, LoPresti ST, Swineheart IT, White LJ, Brown BN, Badylak SF (2017) Macrophage phenotype in response to ECM bioscaffolds. Semin Immunol 29:2-13

100. LoPresti ST, Brown BN (2018) Effect of source animal age upon macrophage response to extracellular matrix biomaterials. J Immunol Regen Med 1:57-66

101. Freitas-Rodriguez S, Folgueras AR, Lopez-Otin C (2017) The role of matrix metalloproteinases in aging: tissue remodeling and beyond. Biochim Biophys Acta, Mol Cell Res 1864:2015-2025

102. Qin Z, Balimunkwe RM, Quan T (2017) Age-related reduction of dermal fibroblast size upregulates multiple matrix metalloproteinases as observed in aged human skin in vivo. Br J Dermatol 177: $1337-1348$

103. Kovtonyuk LV, Fritsch K, Feng X, Manz MG, Takizawa H (2016) Inflamm-aging of hematopoiesis, hematopoietic stem cells, and the bone marrow microenvironment. Front Immunol 7:502

104. Challen GA, Boles NC, Chambers SM, Goodell MA (2010) Distinct hematopoietic stem cell subtypes are differentially regulated by TGF- $\beta 1$. Cell Stem Cell 6:265-278
105. Quere R, Saint-Paul L, Carmignac V, Martin RZ, Chretien ML, Largeot A, Hammann A, Pais de Barros JP, Bastie JN, Delva L (2014) Tifl $\gamma$ regulates the TGF- $\beta 1$ receptor and promotes physiological aging of hematopoietic stem cells. Proc Natl Acad Sci U S A 111(29):10592-10597

106. Zhuang J, Zhang J, Lwin ST, Edwards JR, Edwards CM, Mundy GR, Yang X (2012) Osteoclasts in multiple myeloma are derived from $\mathrm{Gr}-1^{+} \mathrm{CD} 11 \mathrm{~b}^{+}$myeloid-derived suppressor cells. PLoS One 7:e48871

107. Zhang H, Huang Y, Wang S, Fu R, Guo C, Wang H, Zhao J, Gaskin F, Chen J, Yang N, Fu SM (2015) Myeloid-derived suppressor cells contribute to bone erosion in collagen-induced arthritis by differentiating to osteoclasts. J Autoimmun 65:82-89

108. Gumucio JP, Mendias CL (2013) Atrogin-1, MuRF-1, and sarcopenia. Endocrine 43:12-21

109. Quan T, Fisher GJ (2015) Role of age-associated alterations of the dermal extracellular matrix microenvironment in human skin aging: a mini-review. Gerontology 61:427-434

110. Low EL, Baker AH, Bradshaw AC (2019) TGF $\beta$, smooth muscle cells and coronary artery disease: a review. Cell Signal 53:90-101

111. Wyss-Coray T, Masliah E, Mallory M, McConlogue L, JohnsonWood K, Lin C, Mucke L (1997) Amyloidogenic role of cytokine TGF- $\beta 1$ in transgenic mice and in Alzheimer's disease. Nature 389:603-606

112. Carlson ME, Hsu M, Conboy IM (2008) Imbalance between pSmad 3 and Notch induces CDK inhibitors in old muscle stem cells. Nature 454:528-532

113. Narola J, Pandey SN, Glick A, Chen YW (2013) Conditional expression of TGF- $\beta 1$ in skeletal muscles causes endomysial fibrosis and myofibers atrophy. PLoS One 8:e79356

114. Toma I, McCaffrey TA (2012) Transforming growth factor- $\beta$ and atherosclerosis: interwoven atherogenic and atheroprotective aspects. Cell Tissue Res 347:155-175

115. Grammas P, Ovase R (2002) Cerebrovascular transforming growth factor- $\beta$ contributes to inflammation in the Alzheimer's disease brain. Am J Pathol 160:1583-1587

116. Baig S, van Helmond Z, Love S (2009) Tau hyperphosphorylation affects Smad 2/3 translocation. Neuroscience 163:561-570

117. Sun Y, Ma J, Li D, Li P, Zhou X, Li Y, He Z, Qin L, Liang L, Luo $X$ (2019) Interleukin-10 inhibits interleukin-1 $\beta$ production and inflammasome activation of microglia in epileptic seizures. J Neuroinflammation 16:66

118. Mittal SK, Roche PA (2015) Suppression of antigen presentation by IL-10. Curr Opin Immunol 34:22-27

119. Ye Z, Huang H, Hao S, Xu S, Yu H, Van Den Hurk S, Xiang J (2007) IL-10 has a distinct immunoregulatory effect on naive and active T cell subsets. J Interf Cytokine Res 27:1031-1038

120. Hsu P, Santner-Nanan B, Hu M, Skarratt K, Lee CH, Stormon M, Wong M, Fuller SJ, Nanan R (2015) IL-10 potentiates differentiation of human induced regulatory T cells via STAT3 and Foxo1. J Immunol 195:3665-3674

121. Jung M, Ma Y, Iyer RP, DeLeon-Pennell KY, Yabluchanskiy A, Garrett MR, Lindsey ML (2017) IL-10 improves cardiac remodeling after myocardial infarction by stimulating M2 macrophage polarization and fibroblast activation. Basic Res Cardiol 112:33

122. Rosser EC, Mauri C (2015) Regulatory B cells: origin, phenotype, and function. Immunity 42:607-612

123. You L, Wang Z, Li H, Shou J, Jing Z, Xie J, Sui X, Pan H, Han W (2015) The role of STAT3 in autophagy. Autophagy 11:729-739

124. Wu TT, Li WM, Yao YM (2016) Interactions between autophagy and inhibitory cytokines. Int J Biol Sci 12:884-897

125. Ip WKE, Hoshi N, Shouval DS, Snapper S, Medzhitov R (2017) Anti-inflammatory effect of IL-10 mediated by metabolic reprogramming of macrophages. Science 356:513-519

126. Shi J, Wang H, Guan H, Shi S, Li Y, Wu X, Li N, Yang C, Bai X, Cai W, Yang F, Wang X, Su L, Zheng Z, Hu D (2016) IL10 
inhibits starvation-induced autophagy in hypertrophic scar fibroblasts via cross talk between the IL10-IL10R-STAT3 and IL10AKT-mTOR pathways. Cell Death Dis 7:e2133

127. Kishore R, Krishnamurthy P, Garikipati VN, Benedict C, Nickoloff E, Khan M, Johnson J, Gumpert AM, Koch WJ, Verma SK (2015) Interleukin-10 inhibits chronic angiotensin IIinduced pathological autophagy. J Mol Cell Cardiol 89:203-213

128. Salminen A, Kaarniranta K (2009) Regulation of the aging process by autophagy. Trends Mol Med 15:217-224

129. Halvorsen B, Waehre T, Scholz H, Clausen OP, von der Thüsen JH, Müller F, Heimli H, Tonstad S, Hall C, Froland SS, Biessen EA, Damas JK, Aukrust P (2005) Interleukin-10 enhances the oxidized LDL-induced foam cell formation of macrophages by antiapoptotic mechanisms. J Lipid Res 46:211-219

130. Nakamura R, Sene A, Santeford A, Gdoura A, Kubota S, Zapata N, Apte RS (2015) IL10-driven STAT3 signalling in senescent macrophages promotes pathological eye angiogenesis. Nat Commun 6:7847

131. Chakrabarty P, Li A, Ceballos-Diaz C, Eddy JA, Funk CC, Moore B, DiNunno N, Rosario AM, Cruz PE, Verbeeck C, Sacino A, Nix S, Janus C, Price ND, Das P, Golde TE (2015) IL-10 alters immunoproteostasis in APP mice, increasing plaque burden and worsening cognitive behavior. Neuron 85:519-553

132. Gaarenstroom T, Hill CS (2014) TGF- $\beta$ signaling to chromatin: how Smads regulate transcription during self-renewal and differentiation. Semin Cell Dev Biol 32:107-118

133. Wingelhofer B, Neubauer HA, Valent P, Han X, Constantinescu SN, Gunning PT, Müller M, Moriggl R (2018) Implications of STAT3 and STAT5 signaling on gene regulation and chromatin remodeling in hematopoietic cancer. Leukemia 32:1713-1726

134. Wang YQ, Li YM, Li X, Liu T, Liu XK, Zhang JQ, Guo JW, Guo LY, Qiao L (2013) Hypermethylation of TGF- $\beta 1$ gene promoter in gastric cancer. World J Gastroenterol 19:5557-5564

135. Zhang H, Kuchroo V (2019) Epigenetic and transcriptional mechanisms for the regulation of IL-10. Semin Immunol 44:101324

136. Rajbhandari P, Thomas BJ, Feng AC, Hong C, Wang J, Vergnes L, Sallam T, Wang B, Sandhu J, Seldin MM, Lusis AJ, Fong LG, Katz M, Lee R, Young SG, Reue K, Smale ST, Tontonoz P (2018) IL-10 signaling remodels adipose chromatin architecture to limit thermogenesis and energy expenditure. Cell 172:218-233

137. Saraiva M, Christensen JR, Tsytsykova AV, Goldfeld AE, Ley SC, Kioussis D, O'Garra A (2005) Identification of a macrophage-specific chromatin signature in the IL-10 locus. J Immunol 175:1041-1046

138. Lyu G, Guan Y, Zhang C, Zong L, Sun L, Huang X, Huang L, Zhang L, Tian XL, Zhou Z, Tao W (2018) TGF- $\beta$ signaling alters H4K20me3 status via miR-29 and contributes to cellular senescence and cardiac aging. Nat Commun 9:2560

139. May RD, Fung M (2015) Strategies targeting the IL-4/IL-13 axes in disease. Cytokine 75:89-116

140. Peng H, Sarwar Z, Yang XP, Peterson EL, Xu J, Janic B, Rhaleb $\mathrm{N}$, Carretero OA, Rhaleb NE (2015) Profibrotic role for interleukin-4 in cardiac remodeling and dysfunction. Hypertension 66:582-589

141. Kim HD, Yu SJ, Kim HS, Kim YJ, Choe JM, Park YG, Kim J, Sohn J (2013) Interleukin-4 induces senescence in human renal carcinoma cell lines through STAT6 and p38 MAPK. J Biol Chem 288:28743-28754

142. Xu DH, Zhu Z, Wakefield MR, Xiao H, Bai Q, Fang Y (2016) The role of IL-11 in immunity and cancer. Cancer Lett 373:156-163

143. Sumida K, Ohno Y, Ohtake J, Kaneumi S, Kishikawa T, Takahashi N, Taketomi A, Kitamura H (2015) IL-11 induces differentiation of myeloid-derived suppressor cells through activation of STAT3 signalling pathway. Sci Rep 5:13650

144. Corzo CA, Cotter MJ, Cheng P, Cheng F, Kusmartsev S, Sotomayor E, Padhya T, McCaffrey TV, McCaffrey JC,
Gabrilovich DI (2009) Mechanism regulating reactive oxygen species in tumor-induced myeloid-derived suppressor cells. J Immunol 182:5693-5701

145. Kraaij MD, Savage ND, van der Kooij SW, Koekkoek K, Wang J, van den Berg JM, Ottenhoff TH, Kuijpers TW, Holmdahl R, van Kooten C, Gelderman KA (2010) Induction of regulatory T cells by macrophages is dependent on production of reactive oxygen species. Proc Natl Acad Sci U S A 107:17686-17691

146. Xu Q, Choksi S, Qu J, Jang J, Choe M, Banfi B, Engelhardt JF, Liu ZG (2016b) NADPH oxidases are essential for macrophage differentiation. J Biol Chem 291:20030-20041

147. Roux C, Jafari SM, Shinde R, Duncan G, Cescon DW, Silvester J, Chu MF, Hodgson K, Berger T, Wakeham A, Palomero L, Garcia-Valero M, Pujana MA, Mak TW, McGaha TL, Cappello P, Gorrini C (2019) Reactive oxygen species modulate macrophage immunosuppressive phenotype through the up-regulation of PD-L1. Proc Natl Acad Sci U S A 116:4326-4335

148. Nagaraj S, Gupta K, Pisarev V, Kinarsky L, Sherman S, Kang L, Herber DL, Schneck J, Gabrilovich DI (2007) Altered recognition of antigen is a mechanism of $\mathrm{CD} 8^{+} \mathrm{T}$ cell tolerance in cancer. Nat Med 13:828-835

149. Markowitz J, Wang J, Vangundy Z, You J, Yildiz V, Yu L, Foote IP, Branson OE, Stiff AR, Brooks TR, Biesiadecki B, Olencki T, Tridandapani S, Freitas MA, Papenfuss T, Phelps MA, Carson WE (2017) Nitric oxide mediated inhibition of antigen presentation from DCs to $\mathrm{CD}^{+} \mathrm{T}$ cells in cancer and measurement of STAT1 nitration. Sci Rep 7:15424

150. Stiff A, Trikha P, Mundy-Bosse B, McMichael E, Mace TA, Benner B, Kendra K, Campbell A, Gautam S, Abood D, Landi I, Hsu V, Duggan M, Wesolowski R, Old M, Howard JH, Yu L, Stasik N, Olencki T, Muthusamy N, Tridandapani S, Byrd JC, Caligiuri M, Carson WE (2018) Nitric oxide production by myeloid-derived suppressor cells plays a role in impairing Fc receptor-mediated natural killer cell function. Clin Cancer Res 24:1891-1904

151. Beury DW, Carter KA, Nelson C, Sinha P, Hanson E, Nyandjo M, Fitzgerald PJ, Majeed A, Wali N, Ostrand-Rosenberg S (2016) Myeloid-derived suppressor cell survival and function are regulated by the transcription factor Nrf2. J Immunol 196:3470-3478

152. Zhang J, Wang X, Vikash V, Ye Q, Wu D, Liu Y, Dong W (2016) ROS and ROS-mediated cellular signaling. Oxidative Med Cell Longev 2016:4350965

153. Krstic J, Trivanovic D, Mojsilovic S, Santibanez JF (2015) Transforming growth factor- $\beta$ and oxidative stress interplay: implications in tumorigenesis and cancer progression. Oxidative Med Cell Longev 2015:654594

154. Liu RM, Desai LP (2015) Reciprocal regulation of TGF- $\beta$ and reactive oxygen species: a perverse cycle for fibrosis. Redox Biol 6:565-577

155. Kretova M, Sabova L, Hodny Z, Bartek J, Kollarovic G, Nelson BD, Hubackova S, Luciakova K (2014) TGF- $\beta / N F 1 / S m a d 4-m e-$ diated suppression of ANT2 contributes to oxidative stress in cellular senescence. Cell Signal 26:2903-2911

156. Yoon YS, Lee JH, Hwang SC, Choi KS, Yoon G (2005) TGF $\beta 1$ induces prolonged mitochondrial ROS generation through decreased complex IV activity with senescent arrest in Mv1 Lu cells. Oncogene 24:1895-1903

157. Abrigo J, Rivera JC, Simon F, Cabrera D, Cabello-Verrugio C (2016) Transforming growth factor type beta (TGF- $\beta$ ) requires reactive oxygen species to induce skeletal muscle atrophy. Cell Signal 28:366-376

158. Gonzalez-Gonzalez FJ, Chandel NS, Jain M, Budinger GRS (2017) Reactive oxygen species as signaling molecules in the development of lung fibrosis. Transl Res 190:61-68

159. Deng J, Wang X, Qian F, Vogel S, Xiao L, Ranjan R, Park H, Karpurapu M, Ye RD, Park GY, Christman JW (2012) Protective 
role of reactive oxygen species in endotoxin-induced lung inflammation through modulation of IL-10 expression. J Immunol 188: 5734-5740

160. Lind M, Hayes A, Caprnda M, Petrovic D, Rodrigo L, Kruzliak P, Zulli A (2017) Inducible nitric oxide synthase: good or bad? Biomed Pharmacother 93:370-375

161. Santos AL, Sinha S, Lindner AB (2018) The good, the bad, and the ugly of ROS: new insights on aging and aging-related diseases from eukaryotic and prokaryotic model organisms. Oxidative Med Cell Longev 2018:1941285

162. Wall SB, Oh JY, Diers AR, Landar A (2012) Oxidative modification of proteins: an emerging mechanism of cell signaling. Front Physiol 3:369

163. van der Loo B, Labugger R, Skepper JN, Bachschmid M, Kilo J, Powell JM, Palacios-Callender M, Erusalimsky JD, Quaschning T, Malinski T, Gygi D, Ullrich V, Lüscher TF (2000) Enhanced peroxynitrite formation is associated with vascular aging. J Exp Med 192:1731-1744

164. Farah C, Michel LYM, Balligand JL (2018) Nitric oxide signalling in cardiovascular health and disease. Nat Rev Cardiol 15:292316

165. Santhanam L, Christianson DW, Nyhan D, Berkowitz DE (2008) Arginase and vascular aging. J Appl Physiol 105:1632-1642

166. White AR, Ryoo S, Li D, Champion HC, Steppan J, Wang D, Nyhan D, Shoukas AA, Hare JM, Berkowitz DE (2006) Knockdown of arginase I restores NO signaling in the vasculature of old rats. Hypertension 47:245-251

167. Zhu C, Yu Y, Montani JP, Ming XF, Yang Z (2017) Arginase-I enhances vascular endothelial inflammation and senescence through eNOS-uncoupling. BMC Res Notes 10:82

168. Austin SA, Santhanam AV, Hinton DJ, Choi DS, Katusic ZS (2013) Endothelial nitric oxide deficiency promotes Alzheimer's disease pathology. J Neurochem 127:691-700

169. Murray PJ (2016) Amino acid auxotrophy as a system of immunological control nodes. Nat Immunol 17:132-139

170. Caldwell RW, Rodriguez PC, Toque HA, Narayanan SP, Caldwell RB (2018) Arginase: a multifaceted enzyme important in health and disease. Physiol Rev 98:641-665

171. Mellor AL, Lemos H, Huang L (2017) Indoleamine 2,3dioxygenase and tolerance: where are we now? Front Immunol 8:1360

172. Badawy AA (2017) Kynurenine pathway of tryptophan metabolism: regulatory and functional aspects. Int J Tryptophan Res 10: $1-20$

173. Bronte V, Zanovello P (2005) Regulation of immune responses by L-arginine metabolism. Nat Rev Immunol 5:641-654

174. Szefel J, Danielak A, Kruszewski WJ (2019) Metabolic pathways of L-arginine and therapeutic consequences in tumors. Adv Med Sci 64:104-110

175. Riess C, Shokraie F, Classen CF, Kreikemeyer B, Fiedler T, Junghanss C, Maletzki C (2018) Arginine-depleting enzymes an increasingly recognized treatment strategy for therapyrefractory malignancies. Cell Physiol Biochem 51:854-870

176. Kotagale NR, Taksande BG, Inamdar NN (2019) Neuroprotective offerings by agmatine. Neurotoxicology 73:228-245

177. Madeo F, Eisenberg T, Pietrocola F, Kroemer G (2018) Spermidine in health and disease. Science 359:eaan2788

178. Sanchez-Jimenez F, Medina MA, Villalobos-Rueda L, Urdiales JL (2019) Polyamines in mammalian pathophysiology. Cell Mol Life Sci 76:3987-4008

179. Hayes CS, Shicora AC, Keough MP, Snook AE, Burns MR, Gilmour SK (2014) Polyamine-blocking therapy reverses immunosuppression in the tumor microenvironment. Cancer Immunol Res 2:274-285

180. Saxton RA, Sabatini DM (2017) mTOR signaling in growth, metabolism, and disease. Cell 168:960-976
181. Chantranupong L, Scaria SM, Saxton RA, Gygi MP, Shen K, Wyant GA, Wang T, Harper JW, Gygi SP, Sabatini DM (2016) The CASTOR proteins are arginine sensors for the mTORC1 pathway. Cell 165:153-164

182. Wyant GA, Abu-Remaileh M, Wolfson RL, Chen WW, Freinkman E, Danai LV, Vander Heiden MG, Sabatini DM (2017) mTORC1 activator SLC38A9 is required to efflux essential amino acids from lysosomes and use protein as a nutrient. Cell 171:642-654

183. Kapahi P, Chen D, Rogers AN, Katewa SD, Li PW, Thomas EL, Kockel L (2010) With TOR, less is more: a key role for the conserved nutrient-sensing TOR pathway in aging. Cell Metab 11: 453-465

184. Mirzaei H, Suarez JA, Longo VD (2014) Protein and amino acid restriction, aging and disease: from yeast to humans. Trends Endocrinol Metab 25:558-566

185. Tavernarakis N (2008) Ageing and the regulation of protein synthesis: a balancing act? Trends Cell Biol 18:228-235

186. Holmgaard RB, Zamarin D, Li Y, Gasmi B, Munn DH, Allison JP, Merghoub T, Wolchok JD (2015) Tumor-expressed IDO recruits and activates MDSCs in a Treg-dependent manner. Cell Rep $13: 412-424$

187. Ladomersky E, Zhai L, Lauing KL, Bell A, Xu J, Kocherginsky M, Zhang B, Wu JD, Podojil JR, Platanias LC, Mochizuki AY, Prins RM, Kumthekar P, Raizer JJ, Dixit K, Lukas RV, Horbinski C, Wei M, Zhou C, Pawelec G, Campisi J, Grohmann U, Prendergast GC, Munn DH, Wainwright DA (2020) Advanced age increases immunosuppression in the brain and decreases immunotherapeutic efficacy in subjects with glioblastoma. Clin Cancer Res. https://doi.org/10.1158/1078-0432.CCR-19-3874

188. Mezrich JD, Fechner JH, Zhang X, Johnson BP, Burlingham WJ, Bradfield CA (2010) An interaction between kynurenine and the aryl hydrocarbon receptor can generate regulatory $\mathrm{T}$ cells. $\mathrm{J}$ Immunol 185:3190-3198

189. Castilho BA, Shanmugam R, Silva RC, Ramesh R, Himme BM, Sattlegger E (2014) Keeping the eIF2 $\alpha$ kinase Gcn2 in check. Biochim Biophys Acta 1843:1948-1968

190. Pini L, Pievani M, Bocchetta M, Altomare D, Bosco P, Cavedo E, Galluzzi S, Marizzoni M, Frisoni GB (2016) Brain atrophy in Alzheimer's disease and aging. Ageing Res Rev 30:25-48

191. Kilberg MS, Shan J, Su N (2009) ATF4-dependent transcription mediates signaling of amino acid limitation. Trends Endocrinol Metab 20:436-443

192. Ebert SM, Bullard SA, Basisty N, Marcotte GR, Skopec ZP, Dierdorff JM, Al-Zougbi A, Tomcheck KC, DeLau AD, Rathmacher JA, Bodine SC, Schilling B, Adams CM (2020) Activating transcription factor 4 (ATF4) promotes skeletal muscle atrophy by forming a heterodimer with the transcriptional regulator C/EBP $\beta$. J Biol Chem 295:2787-2803

193. Masuda M, Miyazaki-Anzai S, Keenan AL, Shiozaki Y, Okamura K, Chick WS, Williams K, Zhao X, Rahman SM, Tintut Y, Adams CM, Miyazaki M (2016) Activating transcription factor4 promotes mineralization in vascular smooth muscle cells. JCI Insight 1:88646

194. Pitale PM, Gorbatyuk O, Gorbatyuk M (2017) Neurodegeneration: keeping ATF4 on a tight leash. Front Cell Neurosci 11:410

195. Ohno M (2014) Roles of eIF2 $\alpha$ kinases in the pathogenesis of Alzheimer's disease. Front Mol Neurosci 7:22

196. Brown-Borg HM, Buffenstein R (2017) Cutting back on the essentials: can manipulating intake of specific amino acids modulate health and lifespan? Ageing Res Rev 39:87-95

197. Salminen A, Kaarniranta K, Kauppinen A (2017) Integrated stress response stimulates FGF21 expression: systemic enhancer of longevity. Cell Signal 40:10-21 
198. Song P, Ramprasath T, Wang H, Zou MH (2017) Abnormal kynurenine pathway of tryptophan catabolism in cardiovascular diseases. Cell Mol Life Sci 74:2899-2916

199. Maddison DC, Giorgini F (2015) The kynurenine pathway and neurodegenerative disease. Semin Cell Dev Biol 40:134-141

200. Kaiser H, Yu K, Pandya C, Mendhe B, Isales CM, McGeeLawrence ME, Johnson M, Fulzele S, Hamrick MW (2019) Kynurenine, a tryptophan metabolite that increases with age, induces muscle atrophy and lipid peroxidation. Oxidative Med Cell Longev 2019:9894238

201. Refaey ME, McGee-Lawrence ME, Fulzele S, Kennedy EJ, Bollag WB, Elsalanty M, Zhong Q, Ding KH, Bendzunas NG, Shi XM, Xu J, Hill WD, Johnson MH, Hunter M, Pierce JL, Yu K, Hamrick MW, Isales CM (2017) Kynurenine, a tryptophan metabolite that accumulates with age, induces bone loss. J Bone Miner Res 32:2182-2193

202. Sorgdrager FJH, Naude PJW, Kema IP, Nollen EA, Deyn PP (2019) Tryptophan metabolism in inflammaging: from biomarker to therapeutic target. Front Immunol 10:2565

203. Guillemin GJ, Brew BJ, Noonan CE, Takikawa O, Cullen KM (2005) Indoleamine 2,3 dioxygenase and quinolinic acid immunoreactivity in Alzheimer's disease hippocampus. Neuropathol Appl Neurobiol 31:395-404

204. Reyes Ocampo J, Lugo Huitron R, Gonzalez-Esquivel D, UgaldeMuniz P, Jimenez-Anguiano A, Pineda B, Pedraza-Chaverri J, Ríos C, Perez de la Cruz V (2014) Kynurenines with neuroactive and redox properties: relevance to aging and brain diseases. Oxidative Med Cell Longev 2014:646909
205. Liu JJ, Movassat J, Portha B (2019) Emerging role for kynurenines in metabolic pathologies. Curr Opin Clin Nutr Metab Care 22:82-90

206. Wang Q, Zhang M, Ding Y, Wang Q, Zhang W, Song P, Zou MH (2014) Activation of NAD(P)H oxidase by tryptophan-derived 3hydroxykynurenine accelerates endothelial apoptosis and dysfunction in vivo. Circ Res 114:480-492

207. Kondrikov D, Elmansi A, Bragg RT, Mobley T, Barrett T, Eisa N, Kondrikova G, Schoeinlein P, Aguilar-Perez A, Shi XM, Fulzele S, Lawrence MM, Hamrick M, Isales C, Hill W (2020) Kynurenine inhibits autophagy and promotes senescence in aged bone marrow mesenchymal stem cells through the aryl hydrocarbon receptor pathway. Exp Gerontol 130:110805

208. Kaluzna-Czaplinska J, Gątarek P, Chirumbolo S, Chartrand MS, Björklund G (2019) How important is tryptophan in human health? Crit Rev Food Sci Nutr 59:72-88

209. Salminen A, Kaarniranta K, Kauppinen A (2019) Immunosenescence: the potential role of myeloid-derived suppressor cells (MDSC) in age-related immune deficiency. Cell Mol Life Sci 76:1901-1918

210. Dyck L, Mills KHG (2017) Immune checkpoints and their inhibition in cancer and infectious diseases. Eur J Immunol 47:765-779

Publisher's note Springer Nature remains neutral with regard to jurisdictional claims in published maps and institutional affiliations. 